\title{
Crack Detection in Plate-Like Structures Using Modal Strain Energy Method considering Various Boundary Conditions
}

\author{
Thanh-Cao Le $\left.\mathbb{D}^{1}\right)^{1,2,3}$ Duc-Duy Ho $\mathbb{D}^{1,2}$ Thanh-Canh Huynh $\mathbb{D}^{4,5}$ and Van-Sy Bach $\mathbb{D}^{1,2,3}$ \\ ${ }^{1}$ Faculty of Civil Engineering, Ho Chi Minh City University of Technology (HCMUT), Ho Chi Minh City 700000, Vietnam \\ ${ }^{2}$ Vietnam National University Ho Chi Minh City, Ho Chi Minh City 700000, Vietnam \\ ${ }^{3}$ Faculty of Civil Engineering, Nha Trang University, Nha Trang 57100, Vietnam \\ ${ }^{4}$ Faculty of Civil Engineering, Duy Tan University, Da Nang City 550000, Vietnam \\ ${ }^{5}$ Center for Construction, Mechanics and Materials, Institute of Research and Development, Duy Tan University, \\ Da Nang City 550000, Vietnam
}

Correspondence should be addressed to Duc-Duy Ho; hoducduy@hcmut.edu.vn

Received 9 March 2021; Revised 21 April 2021; Accepted 15 May 2021; Published 29 May 2021

Academic Editor: Carlo Rainieri

Copyright $(92021$ Thanh-Cao Le et al. This is an open access article distributed under the Creative Commons Attribution License, which permits unrestricted use, distribution, and reproduction in any medium, provided the original work is properly cited.

Among vibration-based damage detection methods, one of the effective approaches for damage localization is the modal strain energy method. In this paper, the modal strain energy method is developed for damage detection in plate-like structures with various boundary conditions. Firstly, the theory of the modal strain energy method is briefly outlined. In order to overcome the limitation of measuring points, a central difference method is newly employed to compute the partial differential terms in the modal strain energy formula. Finite element analysis is conducted on an aluminum thin plate to obtain the mode shapes before and after the occurrence of damage. Feasibility of the proposed method is verified by investigating plates with different types of boundary conditions. A damage index is presented to identify the location and extent of crack in the plate-like structures. The analytical results show that the proposed method accurately identifies the crack in the plate structure with various types of boundary conditions by using appropriate mode shapes and damage threshold.

\section{Introduction}

For structures, the occurrence of various types of damage during the operation process is inevitable. If these damages are not detected in time, they will cause serious harm to not only the structure itself but also the lives of people. Therefore, structural health monitoring (SHM) is a very necessary field of study and plays a very important role for the safety and longevity of the structure. One of the solutions to ensure the safety and integrity of the structure is to perform SHM regularly so that the damages can be detected early in the initial phase, when they are not dangerous. In recent years, studies on SHM have focused on analyzing the response of structures, developing measurement techniques, developing damage detection methods, and deploying practical applications as discussed by Doebling et al. [1], Farrar [2], Kim [3], and Li [4]. In the nondestructive damage detection methods, vibration-based methods have become one of the common methods in detecting damage and diagnosing structural health. These methods have relatively low cost, use nondestructive technology, and are highly feasible for diagnosing the global health of the structure. In certainty, damages will significantly change the structural properties and lead to changes in vibration characteristics such as natural frequency, mode shape, mode shape curvature, and modal strain energy as discussed by Sohn [5]. In particular, modal strain energy-based damage detection method has emerged with the advantage of both the global SHM method and the local SHM method as mentioned by Fan and Qiao [6].

During the last three decades, the modal strain energybased damage detection method has proved to be highly effective in detecting the structural damages, because the modal strain energy value is more sensitive to damage than 
natural frequency and mode shape. The literature review of modal strain energy method is summarized as follows. Stubbs $[7,8]$ proposed the modal strain energy method to detect the damages in beam-like structures. In these studies, the damage locations were successfully diagnosed in the beams. Cornwell et al. [9] extended the study of modal strain energy method on plate-like structures. A damage index determining from the change in modal strain energy due to the damages was presented to locate the damages. Kim et al. [10] developed a modal strain energy-based damage detection to locate accurately the damages at midspan and quarter-span in a beam by using a few modes. Kim et al. [11] applied this method to monitor the reduction of stiffness in a prestressed reinforced concrete girder. $\mathrm{Hu}$ and $\mathrm{Wu}$ [12] used the differential quadrature method for calculating the modal strain energy in order to detect the location of cracks in a thin aluminum plate with free boundary conditions. Dixit and Hanagud [13] proposed a modal strain energy-based method for assessing damage in beams by using natural frequency, mode shape, and physical characteristics of the structure. Seyedpoor [14] proposed a two-step method to detect location and extent of damage at multiple locations. The first step is to identify the damage's location by using a modal strain energy-based index (MSEDI). The second step is to determine the damage's severity by employing the particle swarm optimization. Cha and Buyukozturk [15] presented a damage detection method combining modal strain energy method and hybrid multiobjective optimization for steel space frame structures. The method is capable of diagnosing structural damages with a minor severity. Vo et al. [16] combined the modal strain energy method and the improved differential evolution algorithm to diagnose the location and the extent of damage for laminated composite plates. The influence of noise phenomena on the detection results was also investigated. Kaveh and Zolghadr [17] used the MSEBI developed by Seyedpoor [14] and the cyclical parthenogenesis algorithm to detect the damage of the elements for the plane frame structures. Dinh [18] presented a two-step method using the normalized modal strain energybased damage index (nMSEDI) and the Jaya algorithm for diagnosing the damages in plates. Two objective functions based on the change in modal flexibility and the change in mode shape were performed. Recently, Samir et al. [19] presented a damage detection method using nMSEDI and teaching-learning-based optimization algorithm to detect the location and the extent of damages in beam-like structures. Wang et al. [20] developed an effective iterative two-stage method for structural damage identification of offshore platform structures. A new damage index, Modal Energy-Based Damage Index (MEBI), was proposed to help effectively locate the potential damage elements in the first step. MEBI is calculated directly from the mode shape and stiff matrixes of every element before and after the occurrence of damage. Then, the beetle antenna search (BAS) algorithm is used to estimate the damage severity of these elements in the next stage. Kourehli [21] proposed an effective model reduction method to overcome the limitation of number sensors using extreme learning machine. The second-order approximation of Neumann series expansion has been used to condense mass and stiffness matrices. Ghannadi et al. [22] presented a reliable approach that combines the grey wolf optimization and expanded mode shapes with system equivalent reduction and expansion process for determining the severities and locations of damage of skeletal structures.

From the previous studies, the modal strain energy method can be classified into two approaches that are direct method and indirect method. For the direct method, the modal strain energy is determined from stiffness matrix and mode shapes. Meanwhile, for the indirect method, the modal strain energy is determined from mode shape curvatures. Determining the stiffness matrix of the real structures is very difficult which leads to the limitation of the direct method. Therefore, the indirect method was chosen to develop in this study. However, the mode shape curvatures which are the second derivative of mode shapes depend on the structural boundary conditions. For the damage localization, the modal strain energy method is not distorted due to presence of noise in comparison to the mode shape curvature; as a result, the modal strain energy method can detect minor damages. Besides, the wavelet method basically bases on the change in mode shapes to localize the damage; as a result, the wavelet method is not as sensitive to damage as the modal strain energy method. However, the modal strain energy method still has some disadvantages such that this method requires normalized mode shape as the input data; it has no ability to identify the extent of structural damage. In addition, plate-like structures are commonly used for fields such as mechanical engineering, aerospace engineering, and civil engineering. For plates, the damages due to the reduction of stiffness (e.g., cracking) are necessary to be diagnosed and monitored in order to ensure the safety and working ability of the structure resisting loads and environmental impacts. So far, there has been no study on the structural damage detection in plates with different boundary conditions using the modal strain energy method. Therefore, it is necessary to develop a modal strain energybased damage detection method for plate-like structures with different boundary conditions.

The main objective of this study is to develop a modal strain energy-based damage detection method for plate-like structures with various boundary conditions. In order to overcome the limitation of measuring points, a central difference method is newly employed to compute the partial differential terms in the modal strain energy formula. A finite element analysis is conducted on an aluminum thin plate to obtain the mode shapes before and after the occurrence of damage. The feasibility of the developed method is verified by investigating plates with different types of boundary conditions (i.e., free conditions, hinged conditions, and fixed conditions). A damage index is proposed to identify the location and extent of crack in the plates. The effect of using different mode shapes and damage thresholds on the accuracy of diagnostic results is also carried out. The analytical results show that the proposed method accurately identifies the crack in the plate-like structures with various types of boundary condition by using appropriate mode shapes and damage threshold. 


\section{Modal Strain Energy-Based Damage Detection Method}

2.1. Theory of Modal Strain Energy Method. Mode shapes which are the main input data for modal strain energy method can be obtained from modal analysis using finite element method. For plate-like structures, the mode shape can be represented by a two-dimensional surface. In this study, a thin rectangular plate divided into elements as shown in Figure 1 is analyzed for undamped free vibration, where $N_{x}$ and $N_{y}$ are the number of element for $x$-direction and $y$-direction, respectively; 4-point coordinates of the element $(i, j)$ are $\left(x_{i}, y_{j}\right)$, $\left(x_{i+1}, y_{j}\right),\left(x_{j}, y_{j+1}\right)$, and $\left(x_{i+1}, y_{j+1}\right)$, respectively.

For the $k^{t h}$ mode shape, $\phi_{k}(x, y)$, the modal strain energy for the element $(i, j)$ is determined as follows [9]:

$$
\begin{aligned}
U_{k, i j}= & \frac{D_{i j}}{2} \int_{x_{i}}^{x_{i+1}} \int_{y_{j}}^{y_{j+1}}\left[\left(\frac{\partial^{2} \phi_{k}}{\partial^{2} x}\right)^{2}+\left(\frac{\partial^{2} \phi_{k}}{\partial^{2} y}\right)^{2}\right. \\
& \left.+2 \nu\left(\frac{\partial^{2} \phi_{k}}{\partial^{2} x}\right)\left(\frac{\partial^{2} \phi_{k}}{\partial^{2} y}\right)+2(1-v)\left(\frac{\partial^{2} \phi_{k}}{\partial x \partial y}\right)^{2}\right\rceil \mathrm{d} x \mathrm{~d} y
\end{aligned}
$$

where $D_{i j}$ is the flexural stiffness of the element $(i, j) ; v$ is Poisson's ratio.

Also for the $k^{\text {th }}$ mode shape, the modal strain energy for the whole plate is determined as follows:

$$
U_{k}=\sum_{i=1}^{N_{x}} \sum_{j=1}^{N_{y}} U_{k, i j}
$$

After the occurrence of damage caused by the reduction of flexural stiffness, the $k^{\text {th }}$ mode shape is changed as $\phi_{k}^{*}(x, y)$. For the damaged state, the modal strain energy for the element $(i, j)$ of $U_{k, i j}^{*}$ and the modal strain energy for the whole plate of $U_{k}^{*}$ are determined similarly as (1) and (2), respectively. The fractional modal strain energies for the element $(i, j)$ are determined as follows:

$$
\begin{gathered}
F_{k, i j}=\frac{U_{k, i j}}{U_{k}}, \\
F_{k, i j}^{*}=\frac{U_{k, i j}^{*}}{U_{k}^{*}},
\end{gathered}
$$

where $\sum_{i=1}^{N_{x}} \sum_{j=1}^{N_{y}} F_{k, i j}=1$ và $\sum_{i=1}^{N_{x}} \sum_{j=1}^{N_{y}} F_{k, i j}^{*}=1$.

Considering $m$ modes, a damage index for the element $(i, j)$ is defined as follows:

$$
\beta_{i j}=\frac{\sum_{k=1}^{m} F_{k, i j}^{*}}{\sum_{k=1}^{m} F_{k, i j}} .
$$

Then, a normalized damage index is proposed as follows:

$$
Z_{i j}=\frac{\beta_{i j}-\bar{\beta}_{i j}}{\sigma_{i j}},
$$

where $\bar{\beta}_{i j}, \sigma_{i j}$ are mean value and standard deviation, respectively, of the damage indices which are determined as follows:

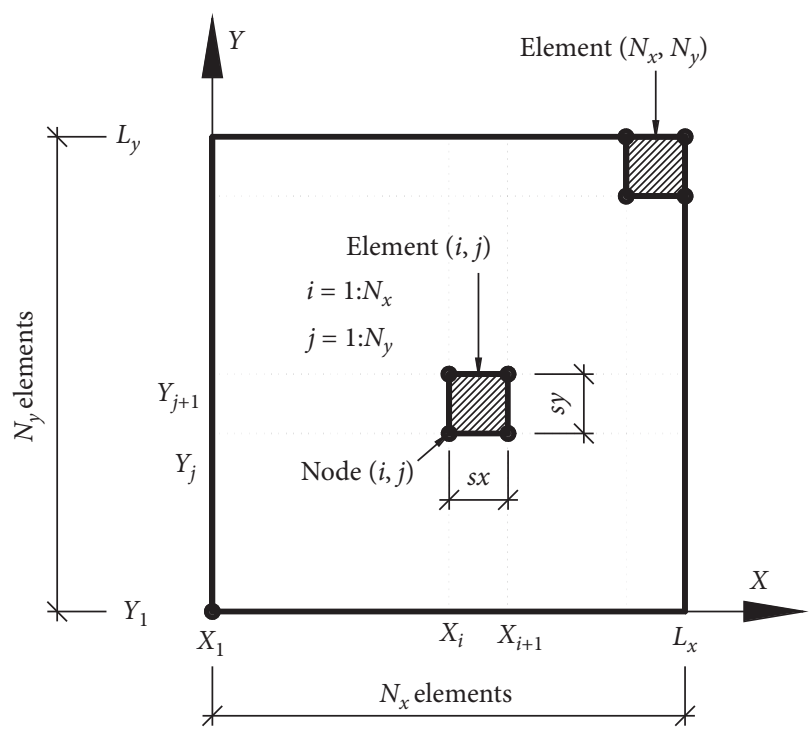

Figure 1: Element diagram for rectangular plate.

$$
\begin{aligned}
\bar{\beta}_{i j} & =\frac{\sum_{i=1}^{N_{x}} \sum_{j=1}^{N_{y}} \beta_{i j}}{\sum_{k=1}^{m} F_{k, i j}}, \\
\sigma_{i j} & =\sqrt{\frac{\left(N_{x} N_{y}\right)\left(\sum_{i=1}^{N_{x}} \sum_{j=1}^{N_{y}}\left(\beta_{i j}\right)^{2}\right)-\left(\sum_{i=1}^{N_{x}} \sum_{j=1}^{N_{y}}\left(\beta_{i j}\right)\right)^{2}}{\left(N_{x} N_{y}\right)\left(N_{x} N_{y}-1\right)}} .
\end{aligned}
$$

The normalized damage index, $Z_{i j}$, is utilized to locate the damage occurring in the plates. In order to determine the modal strain energy following (1), the second derivative of mode shapes (mode shape curvatures) must be carried out. In this study, the central difference method (CDM) is employed to calculate the mode shape curvatures.

\subsection{Modal Strain Energy-Based Damage Detection Procedure.} Based on the theory of modal strain energy-based damage detection method described in the previous section, a damage detection procedure for plate-like structures is proposed in this study. The procedure has seven steps as follows.

\section{Step 1: Get the Mode Shape Data}

The mode shape data can be obtained from the modal analysis of the target structure's free vibration. In this work, the plate-like structure is analyzed by using finite element method. Therein, the plate with certain boundary conditions is modeled for two states which were undamaged state and damaged state. As a result, the plate's mode shape data are obtained for both undamaged state and damaged state.

Step 2: Determine the Mode Shape Curvatures

The mode shape curvatures which are the second derivative of mode shapes are determined by employing the central difference method as follows.

For the inside joints $\left(i=2,3, \ldots, N_{x} ; j=2,3\right.$, $\left.\ldots, N_{y}\right)$ : 


$$
\begin{aligned}
& \frac{\partial^{2} \phi_{k, i j}}{\partial^{2} x}=\frac{\phi_{k,(i-1) j}-2 \phi_{k, i j}+\phi_{k,(i+1) j}}{(s x)^{2}}, \\
& \frac{\partial^{2} \phi_{k, i j}}{\partial^{2} y}=\frac{\phi_{k, i(j-1)}-2 \phi_{k, i j}+\phi_{k, i(j+1)}}{(s y)^{2}},
\end{aligned}
$$

where $s x, s y$ are the mesh size of $x$-direction and $y$ direction, respectively.

For the boundary joints, considering a rectangular plate, the mode shape curvatures at four boundaries $(i=1$, $\left.N_{x}+1 ; j=1, N_{y}+1\right)$ are determined as follows:

Boundary $x=0\left(i=1 ; j=1,2, \ldots, N_{y}+1\right)$

$$
\frac{\partial^{2} \phi_{k, 1 j}}{\partial^{2} x}=\frac{\phi_{k, 0 j}-2 \phi_{k, 1 j}+\phi_{k, 2 j}}{(s x)^{2}} .
$$

Boundary $x=L_{x}\left(i=N_{x}+1 ; j=1,2, \ldots, N_{y}+1\right)$

$$
\frac{\partial^{2} \phi_{k,\left(N_{x}+1\right) j}}{\partial^{2} x}=\frac{\phi_{k, N_{x} j}-2 \phi_{k,\left(N_{x}+1\right) j}+\phi_{k,\left(N_{x}+2\right) j}}{(s x)^{2}} .
$$

Boundary $y=0\left(i=1,2, \ldots, N_{x}+1 ; j=1\right)$

$$
\frac{\partial^{2} \phi_{k, i 1}}{\partial^{2} y}=\frac{\phi_{k, i 0}-2 \phi_{k, i 1}+\phi_{k, i 2}}{(s y)^{2}} .
$$

Boundary $y=L_{y}\left(i=1,2, \ldots, N_{x}+1 ; j=N_{y}+1\right)$

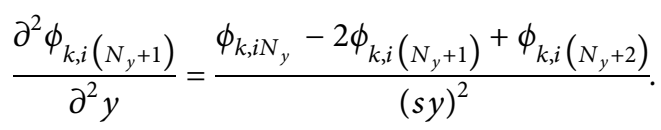

Obviously, the central difference method utilizes the mode shape data of three continuous joints to determine the mode shape curvatures. There is no problem for the inside joints having sufficient mode shape data. However, there is a lack of mode shape data to calculate the mode shape curvatures for the boundary joints following (9)-(12). The mode shape data such as $\phi_{k, 0 j}, \phi_{k,\left(N_{x}+2\right) j}, \phi_{k, i 0}, \phi_{k, i\left(N_{y}+2\right)}$ cannot be obtained from the modal analysis (in Step 1) due to the fact that they belong to outside joints of the target plate. In order to overcome the problem, the virtual boundaries are newly proposed in this study. The rectangular plate has four virtual boundaries with total of $2\left(N_{x}+1\right)+2\left(N_{y}+1\right)$ virtual joints as shown in Figure 2 .

The mode shape data at the virtual joints are found by the extrapolation method. A curve connecting three continuous joints is considered. Then, the mode shape data at the virtual joints are taken symmetrically or antisymmetrically depending on the boundary condition through the corresponding real boundaries.

For free boundary conditions and hinged boundary conditions, the antisymmetrical rule is proposed as follows:

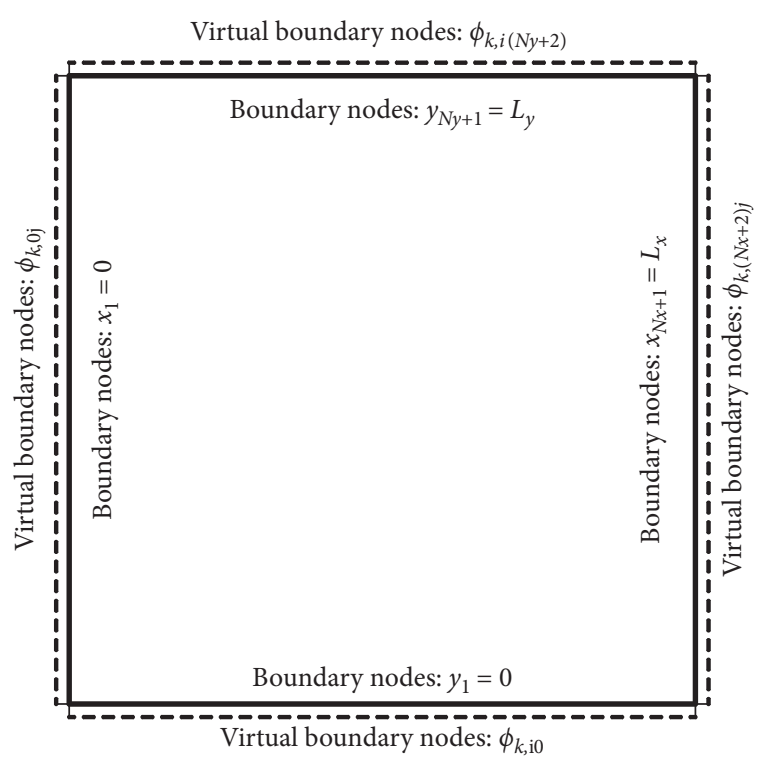

Figure 2: Rectangular plate with virtual boundaries.

$$
\begin{aligned}
\phi_{k, 0 j} & =-\phi_{k, 2 j}, \\
\phi_{k,\left(N_{x}+2\right) j} & =-\phi_{k, N_{x} j}, \\
\phi_{k, i 0} & =-\phi_{k, i 2}, \\
\phi_{k, i}\left(N_{y}+2\right) & =-\phi_{k, i N_{y}} .
\end{aligned}
$$

For fixed boundary conditions, the symmetrical rule is proposed as follows:

$$
\begin{aligned}
\phi_{k, 0 j} & =\phi_{k, 2 j}, \\
\phi_{k,\left(N_{x}+2\right) j} & =\phi_{k, N_{x} j}, \\
\phi_{k, i 0} & =\phi_{k, i 2}, \\
\phi_{k, i}\left(N_{y}+2\right) & =\phi_{k, i N_{y}} .
\end{aligned}
$$

The quantity of $\left(\partial^{2} \phi_{k} / \partial x \partial y\right)$ in (1) is determined by taking the first derivative of mode shapes for $y$-variable, then taking the first derivative of mode shapes for $x$ variable.

\section{Step 3: Determine the Modal Strain Energy}

The modal strain energies for each element and for the whole plate corresponding to undamaged state and damaged state are determined in this step. For $k^{\text {th }}$ mode shape, $\phi_{k}(x, y)$, the modal strain energies for element $(i, j)$ are determined by $(1)$; meanwhile, the modal strain energies for the whole plate are determined by (2).

Step 4: Determine the Fractional Modal Strain Energy The fractional modal strain energies for element $(i, j)$ corresponding to undamaged state and damaged state are determined by (3) and (4), respectively.

Step 5: Determine the Normalized Damage Index

The damage index for element $(i, j)$ using $m$ mode is determined by (5). Then, the normalized damage index is determined by (6). 
Step 6: Detect the Location and Length of Damage In this study, a damage threshold, $Z_{o}$, is presented to alarm the occurrence of damage. The damage threshold, $Z_{o}$, is calculated by percentage of the maximum damage index, $Z_{i j}^{\max }$. If $Z_{i j} \geq Z_{o}$, then the element $(i, j)$ is damaged; otherwise, the element $(i, j)$ is undamaged. The location and length of damage are determined by using the damage index chart after truncation. Figure 3 shows an illustration of the damage index chart for plate-like structures.

Step 7: Assess the Capacity of Damage Detection

Based on the length of damage determined from Step 6, a detection capacity indicator (DCI) is proposed to assess the capacity of damage detection as follows:

$$
\text { DCI }=\frac{L_{\text {pred }}}{L_{\text {real }}} \times 100 \%,
$$

where $L_{\text {pred }}$ is the predicted length of damage obtained from the damage index chat; $L_{\text {real }}$ is the real length of damage. In this work, the assessment of capacity of damage detection is presented as in the three following levels:

(i) If $0 \leq \mathrm{DCI}<50 \%$, the capacity of damage detection is low $(\mathrm{L})$

(ii) $50 \% \leq \mathrm{DCI} \leq 80 \%$ : the capacity of damage detection is average $(\mathrm{A})$

(iii) If $80 \%<\mathrm{DCI} \leq 100 \%$, the capacity of damage detection is high $(\mathrm{H})$

\section{Numerical Verification}

In order to verify the feasibility of the proposed method, a rectangular thin plate with various boundary conditions was investigated in this study. As shown in Figure 4, the plate's dimensions are $240 \mathrm{~mm}$ in length, $240 \mathrm{~mm}$ in width, and $2 \mathrm{~mm}$ in thickness. A crack with $40 \mathrm{~mm}$ in length, $10 \mathrm{~mm}$ in width, and with stiffness reductions equal to $50 \%$ is considered as damage in the plate. The location of the crack is also shown in Figure 4. The material of the plate is aluminum with properties such as elastic modulus of $E=70 \mathrm{GPa}$, Poisson's ratio of $\nu=0.33$, and mass density of $\rho=2735 \mathrm{~kg} /$ $\mathrm{m}^{3}$. In this work, three cases of common boundary conditions restrained for the plate's four sides were examined as follows: case 1-free conditions, case 2-hinged conditions, and case 3-fixed conditions.

To get the mode shape data, the plate was modeled and analyzed using the finite element method. It should be noted that the proposed modal strain energy-based damage detection method is an inverse diagnosis problem, the input data needs only the mode shapes. For the target plate, the first four bending modes corresponding to before and after the crack's occurrence were utilized. From these input data, through the seven analysis steps of the proposed procedure, the output detection results are the occurrence, the location, the predicted length of crack, and the detection capacity indicator. In this study, the damage detection results of the target plate were investigated for four cases depending on the number of modes using:
(1) Separate modes

(2) A combination of two first modes

(3) A combination of three first modes

(4) A combination of four first modes

The following results are analyzed and evaluated: change in natural frequencies and mode shapes, mesh size of element, crack detection, effect of damage threshold and mode on damage detection results.

3.1. Natural Frequencies and Mode Shapes. The target plate's natural frequencies and mode shapes for the first four bending modes were obtained from the modal analysis. In this work, the convergence of natural frequencies depending on the mesh size of the element was evaluated. The mesh sizes of $2 \times 2,4 \times 4,8 \times 8,12 \times 12,24 \times 24$, and $48 \times 48$ were considered. Table 1 shows the change in natural frequencies of undamaged plates due to the mesh sizes. Table 2 shows the convergence of natural frequencies of undamaged plates compared to ones for the mesh size of $48 \times 48$. It is clear that with the mesh sizes of $24 \times 24$, the natural frequencies of the four first modes are almost equal to those of the mesh sizes of $48 \times 48$. Therefore, the mesh size of $24 \times 24$ is good enough to model and analyze the vibration of the plate. Figures 5-7 show the first four bending mode shapes of undamaged plates for case 1 , case 2 , and case 3 , respectively.

The variations of natural frequencies and mode shapes can be used to detect the crack's occurrence in plates. Table 3 shows the variation of natural frequencies due to the crack. The natural frequencies were decreased $0.03 \%-0.8 \%$ as the crack occurred. Table 4 shows the modal assurance criterion (MAC) [5] calculated from the change in mode shapes due to the crack. The MAC values were also decreased as the crack occurred. However, the variations of natural frequencies and mode shapes due to the crack were trivial. As a result, it is hard to detect the crack's occurrence by using less sensitive characteristics to damage such as natural frequency and mode shape. Otherwise, modal strain energy which is determined by using the second derivative of mode shapes is more sensitive to damage than natural frequency and mode shape. Moreover, modal strain energy-based damage detection method can identify not only the occurrence of crack but also the location and the length of crack.

3.2. Mesh Size of Element. In order to investigate the effect of mesh size on damage detection results, three mesh sizes of $12 \times 12,24 \times 24$, and $48 \times 48$ were selected in this study. Figure 8 shows the damage index chart of case 1 for different mesh sizes. As shown in the figure, the location of crack can be detected by using mesh size of $12 \times 12$. The more mesh size's density increases, the higher accuracy of crack's detection is. In this study, the mesh size of $48 \times 48$ was utilized in order to enhance the accuracy of crack detection results.

3.3. Crack Detection. As mentioned in Step 6 of the previous section, an element is considered as damage if its normalized damage index is larger than the damage threshold. 

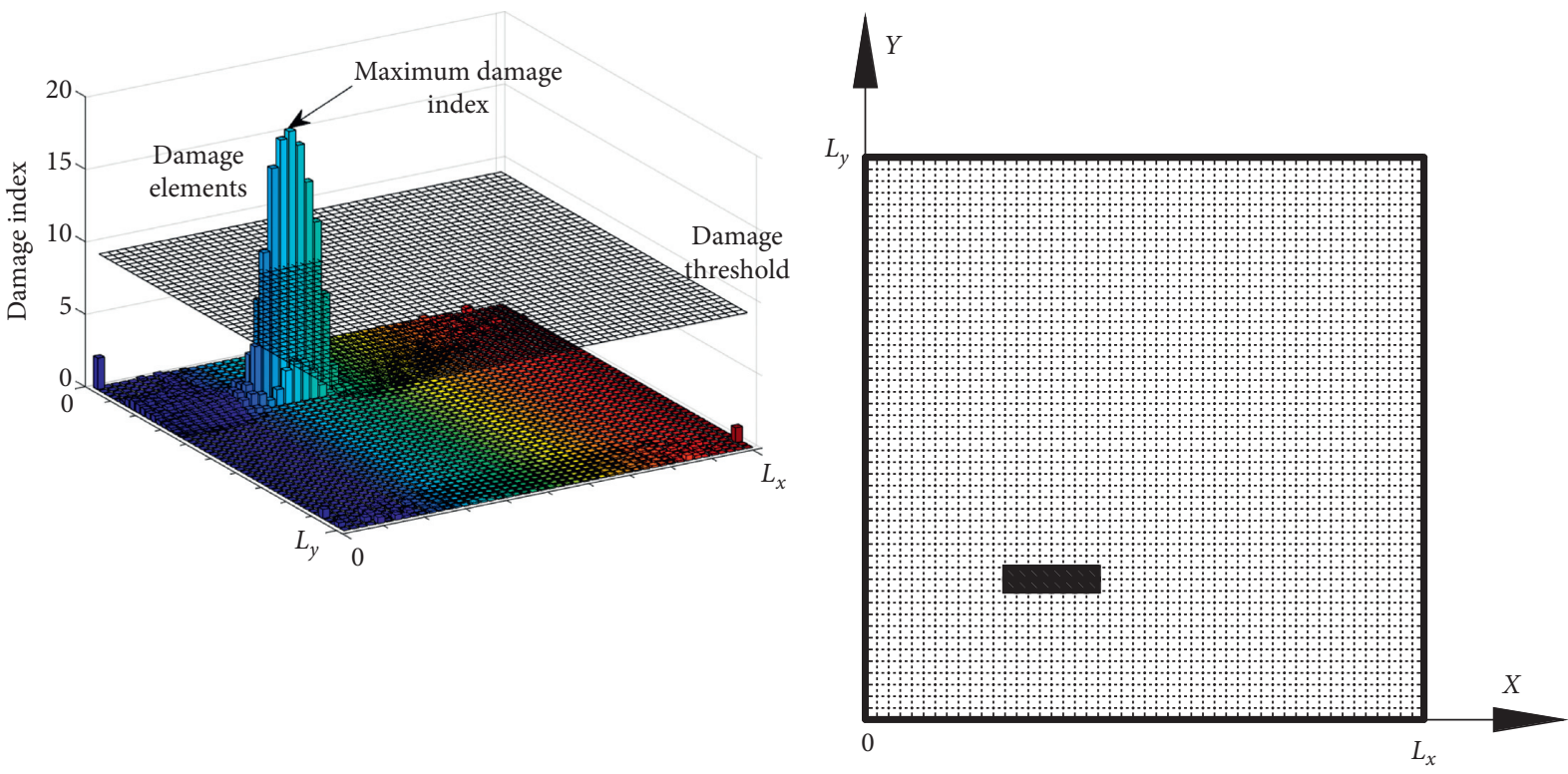

(a)

(b)

Figure 3: Damage index chart. (a) Before truncation. (b) After truncation.

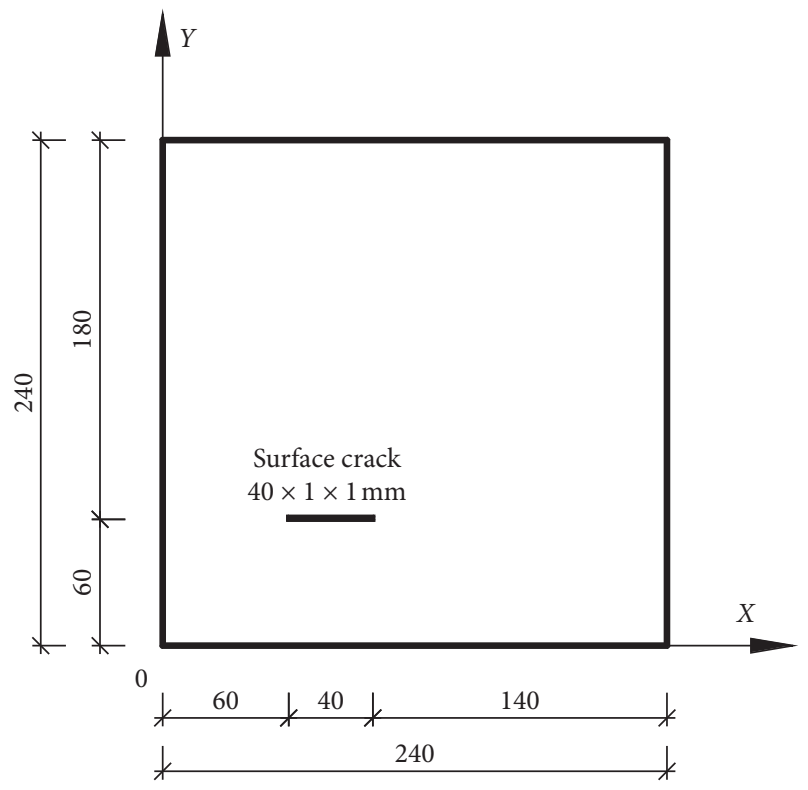

Figure 4: Square plate with a crack.

Figures 9-11 show the damage index chart after truncation with damage threshold of $Z_{0}=50 \% Z_{i j}^{\max }$ for case 1 , case 2 , and case 3, respectively. As shown in the figures, the crack's location and length are detected by using the damage index chart after truncation. The results of crack detection for the target plate are summarized in Tables 5-7 for case 1, case 2, and case 3 , respectively. It should be noted that the damage thresholds of $20 \% Z_{i j}^{\max }, 30 \% Z_{i j}^{\max }, 40 \% Z_{i j}^{\max }, 50 \% Z_{i j}^{\max }$, $60 \% Z_{i j}^{\max }$, and $70 \% Z_{i j}^{\max }$, and the use of different modes were investigated in this study.

As shown in Figures 9-11, the damage indexes usually reach the maximum value in the center of the crack region.
Around this crack region, the damage indexes decrease. This phenomenon is caused by the continuity of the mode shapes. When a subregion is damaged, it will affect neighboring subregions. As a result, the neighboring subregions' damage indexes also increase which causes the noises for damage detection results. Elements near the marginal edge of the crack are usually overdetected if low damage threshold is used and are usually missing detection if high damage threshold is used. As listed in Tables 5-7, the damage capacity indicators (DCI) are different for each damage threshold and each mode. Most of DCI are high $(\mathrm{H})$; this proves that the proposed method has high accuracy for crack detection in plate-like structures. In general, the combination of three first modes (i.e., mode 1, 2, 3) and damage threshold of $30 \% Z_{i j}^{\max }$ is good enough to detect accurately the crack's location and length for the target plate.

\subsection{Effect of Damage Threshold on Damage Detection Results.} The crack detection results are determined by using a damage threshold taken as a percentage for the maximum damage index. The crack's location and length are filtered out and shown on the damage index chart after truncation. This chart gives a visual view of the crack's location as well as the crack's length. The results of this study show that the crack detections are different with different damage thresholds for the same mode. As listed in Tables 5-7, only some cases give the DCI of $100 \%$ at the damage threshold of $30 \% Z_{i j}^{\max }$ for using single mode: mode 3 for case 1 ; modes 1 , 2 , and 3 for case 2 ; and mode 4 for case 3 . For using the combined modes, all cases give the DCI of $100 \%$ at the damage threshold of $30 \% Z_{i j}^{\max }$. The damage threshold of $30 \% Z_{i j}^{\max }$ gives the crack detection's results better than the damage threshold of $20 \% Z_{i j}^{\max }$. In damage threshold of $20 \% Z_{i j}^{\max }$, some subregions near the actual crack are wrongly 
TABLE 1: Change in natural frequencies $(\mathrm{Hz})$ of undamaged plates due to mesh sizes.

\begin{tabular}{|c|c|c|c|c|c|c|}
\hline \multirow{2}{*}{ Mode } & \multicolumn{6}{|c|}{ Mesh size } \\
\hline & $2 \times 2$ & $4 \times 4$ & $8 \times 8$ & $12 \times 12$ & $24 \times 24$ & $48 \times 48$ \\
\hline \multicolumn{7}{|c|}{ Case 1: free conditions } \\
\hline 1 & 119.49 & 115.75 & 113.43 & 112.75 & 112.36 & 112.29 \\
\hline 2 & 194.37 & 175.42 & 167.54 & 165.97 & 164.92 & 164.66 \\
\hline 3 & 230.03 & 232.92 & 214.65 & 211.24 & 209.27 & 208.72 \\
\hline 4 & 268.33 & 300.71 & 297.02 & 294.35 & 292.43 & 291.82 \\
\hline \multicolumn{7}{|c|}{ Case 2: hinged conditions } \\
\hline 1 & 167.24 & 172.57 & 169.64 & 168.89 & 168.16 & 167.92 \\
\hline 2 & 14225 & 547.18 & 447.1 & 431.86 & 422.97 & 420.79 \\
\hline 3 & 22517 & 901.84 & 720.1 & 691.63 & 675.48 & 671.69 \\
\hline 4 & 24622 & 1797.7 & 986.67 & 900.83 & 854.87 & 843.92 \\
\hline \multicolumn{7}{|c|}{ Case 3: fixed conditions } \\
\hline 1 & 5633.4 & 367.42 & 320.07 & 312.75 & 308.53 & 307.49 \\
\hline 2 & 14225 & 1126.2 & 699.68 & 656.37 & 633.06 & 627.51 \\
\hline 3 & 414212 & 1643.2 & 1033.2 & 968.05 & 932.69 & 924.23 \\
\hline 4 & - & 11317 & 1435.9 & 1241.6 & 1148 & 1126.7 \\
\hline
\end{tabular}

Table 2: Convergence of natural frequencies (\%) compared to ones for mesh size of $48 \times 48$.

\begin{tabular}{|c|c|c|c|c|c|}
\hline \multirow{2}{*}{ Mode } & \multicolumn{5}{|c|}{ Mesh size } \\
\hline & $2 \times 2$ & $4 \times 4$ & $8 \times 8$ & $12 \times 12$ & $24 \times 24$ \\
\hline \multicolumn{6}{|c|}{ Case 1: free conditions } \\
\hline 1 & 6.4 & 3.1 & 1.0 & 0.4 & 0.1 \\
\hline 2 & 18.0 & 6.5 & 1.7 & 0.8 & 0.2 \\
\hline 3 & 10.2 & 11.6 & 2.8 & 1.2 & 0.3 \\
\hline 4 & 8.0 & 3.0 & 1.8 & 0.9 & 0.2 \\
\hline \multicolumn{6}{|c|}{ Case 2: hinged conditions } \\
\hline 1 & 0.4 & 2.8 & 1.0 & 0.6 & 0.1 \\
\hline 2 & 3280.5 & 30.0 & 6.3 & 2.6 & 0.5 \\
\hline 3 & 3252.2 & 34.3 & 7.2 & 3.0 & 0.6 \\
\hline 4 & 2817.5 & 113.0 & 16.9 & 6.7 & 1.3 \\
\hline \multicolumn{6}{|c|}{ Case 3: fixed conditions } \\
\hline 1 & 1732.0 & 19.5 & 4.1 & 1.7 & 0.3 \\
\hline 2 & 2166.9 & 79.5 & 11.5 & 4.6 & 0.9 \\
\hline 3 & 44716.9 & 77.8 & 11.8 & 4.7 & 0.9 \\
\hline 4 & - & 904.5 & 27.4 & 10.2 & 1.9 \\
\hline
\end{tabular}

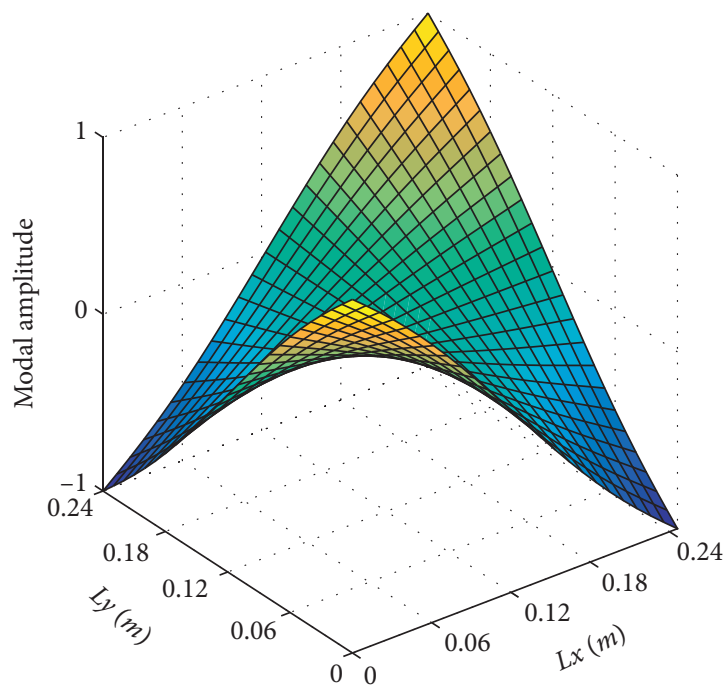

(a)

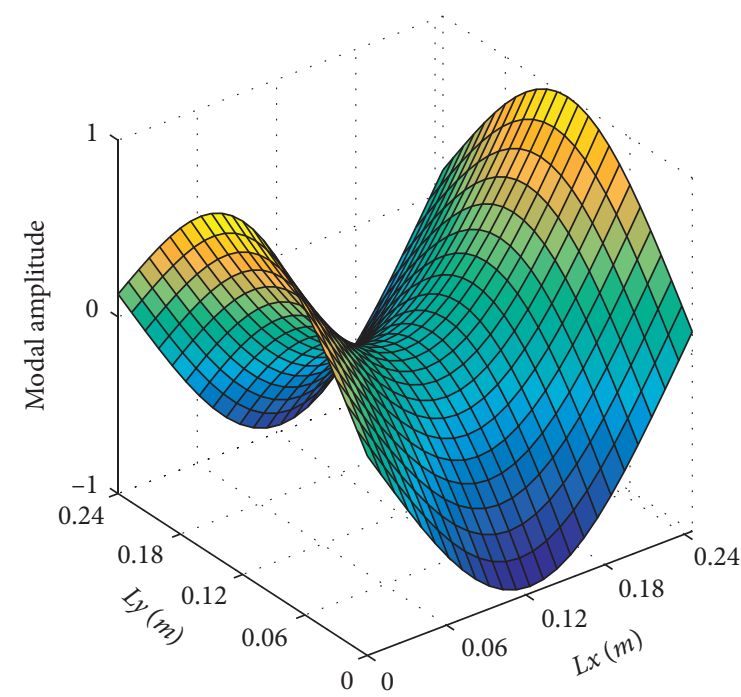

(b)

Figure 5: Continued. 


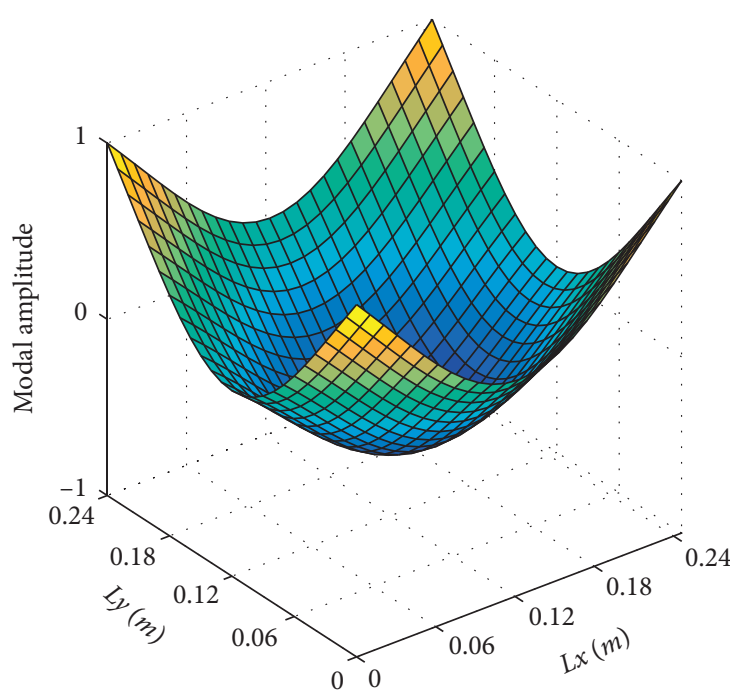

(c)

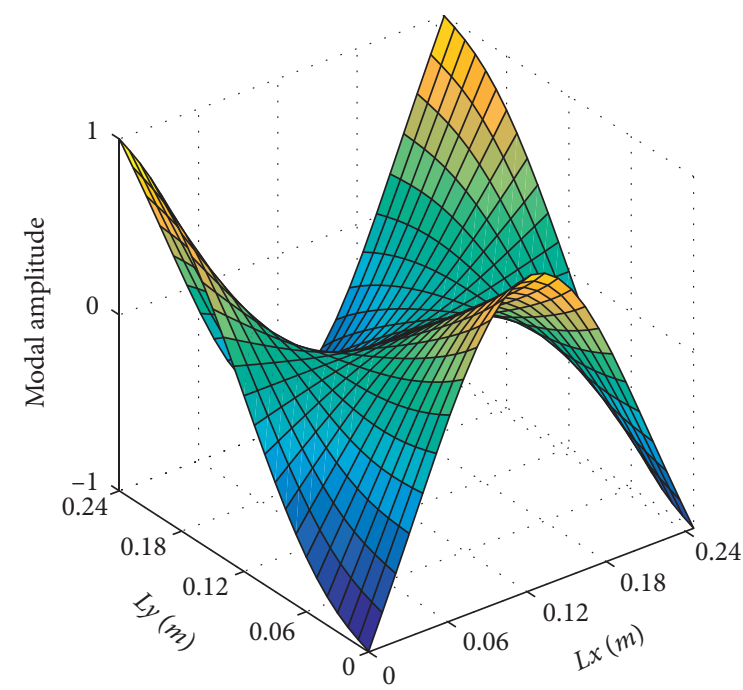

(d)

Figure 5: The first four bending mode shapes of undamaged, free conditions plate. (a) Mode 1. (b) Mode 2. (c) Mode 3. (d) Mode 4.

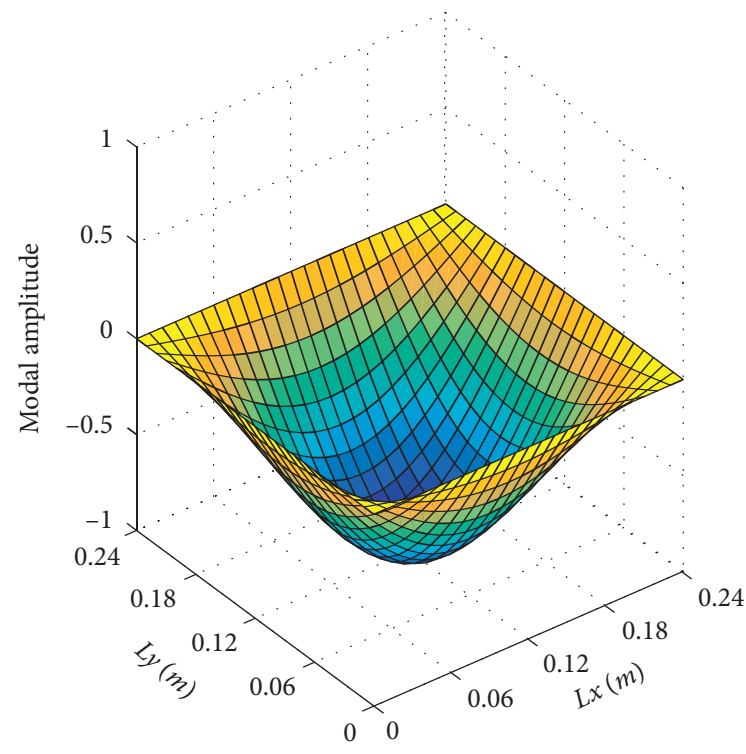

(a)

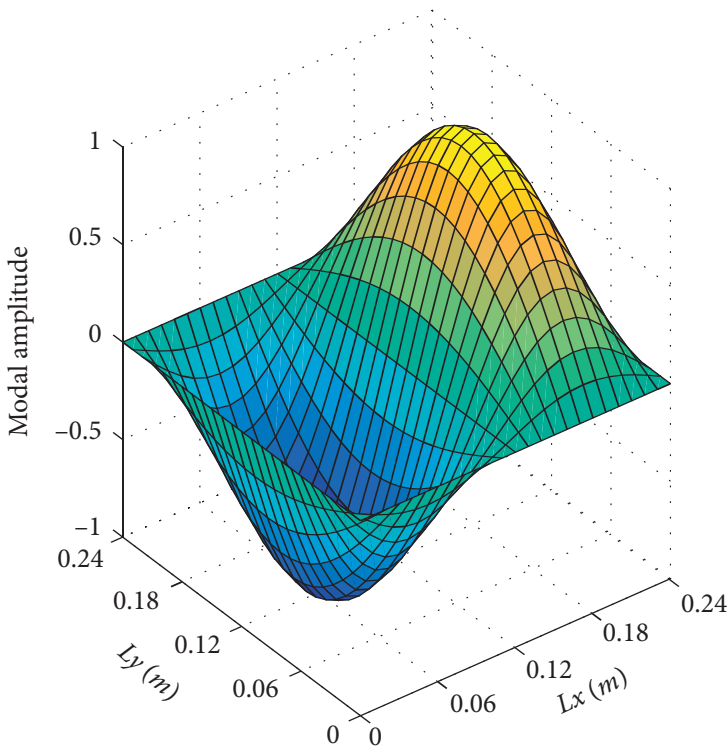

(b)

Figure 6: Continued. 


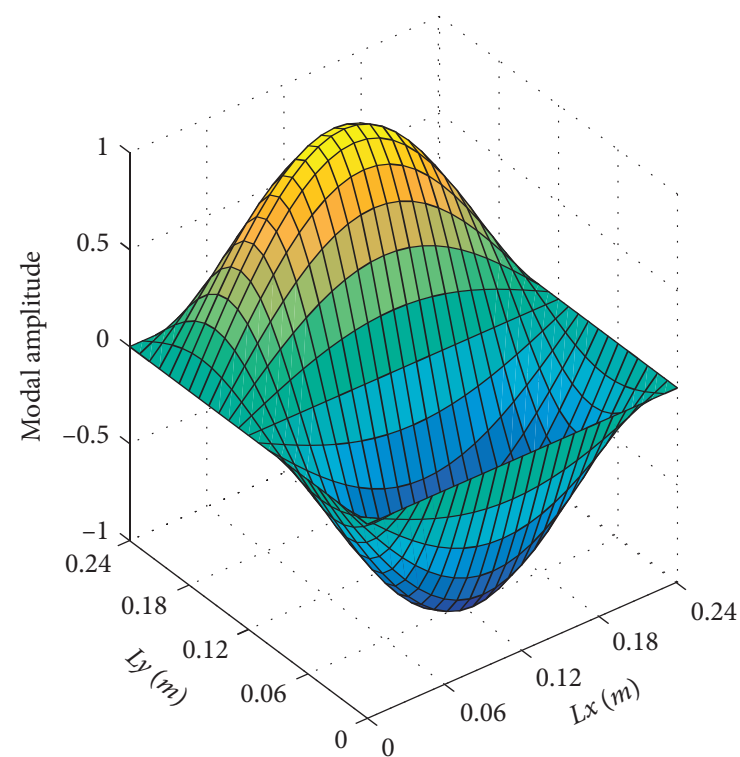

(c)

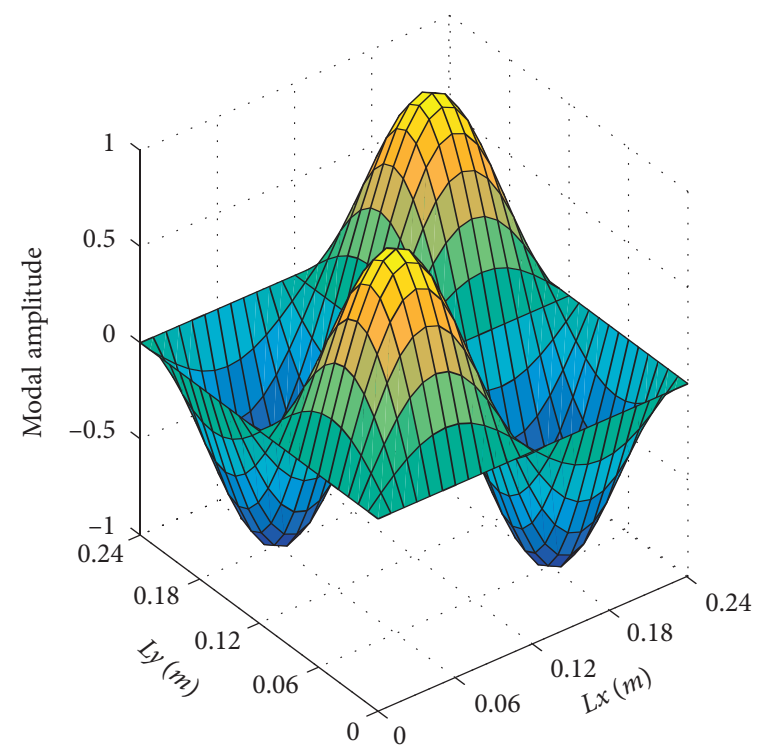

(d)

Figure 6: The first four bending mode shapes of undamaged, hinged conditions plate. (a) Mode 1. (b) Mode 2. (c) Mode 3. (d) Mode 4.

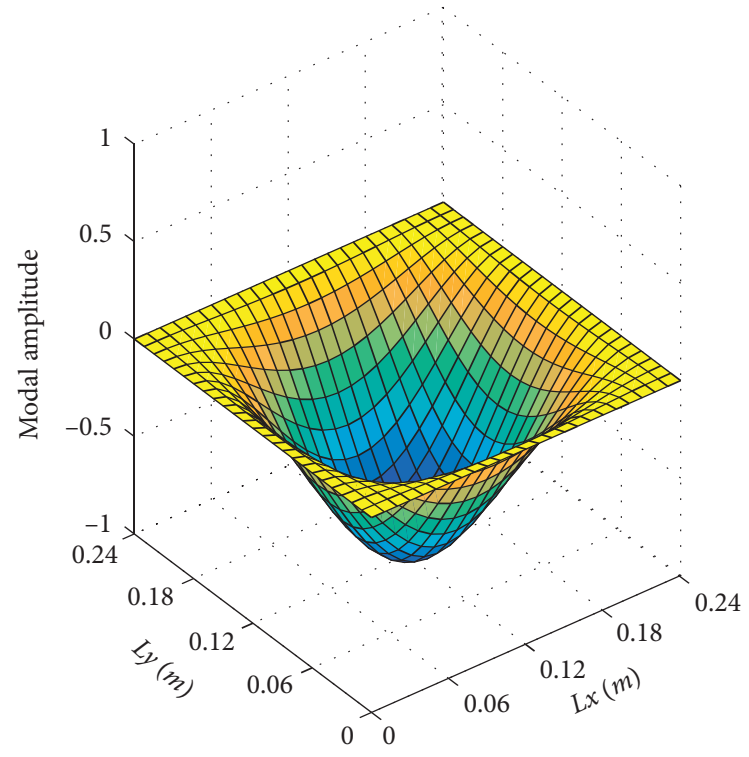

(a)

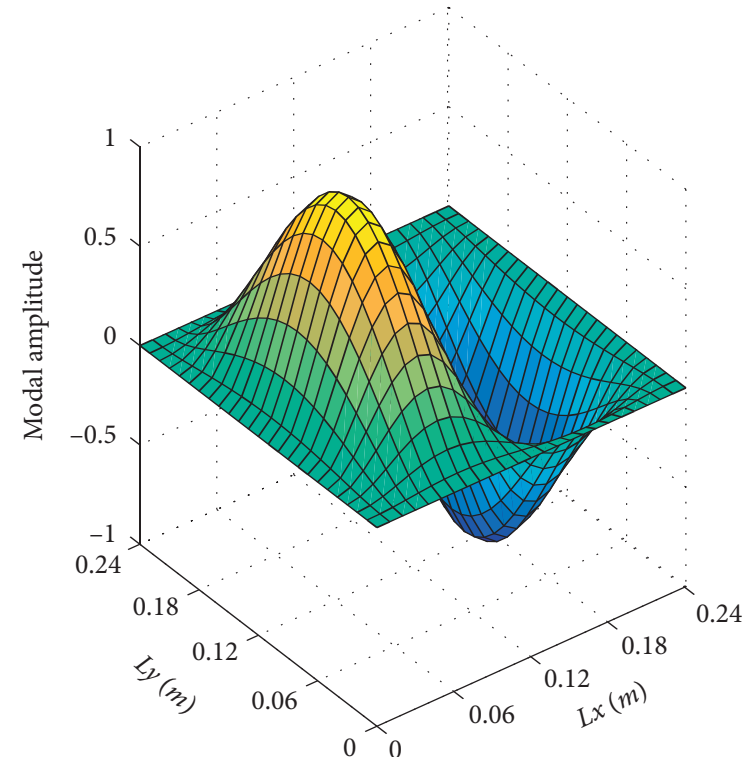

(b)

Figure 7: Continued. 


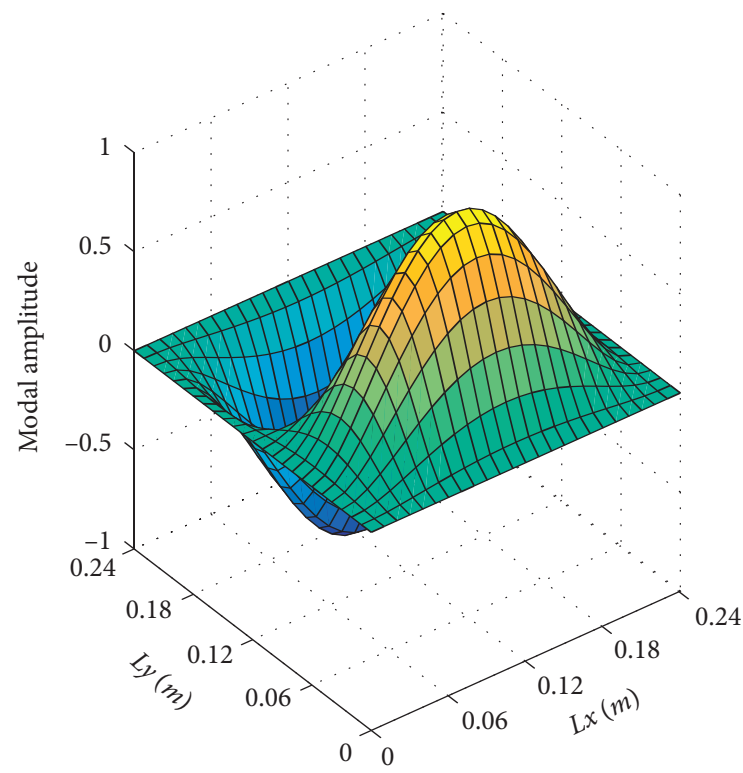

(c)

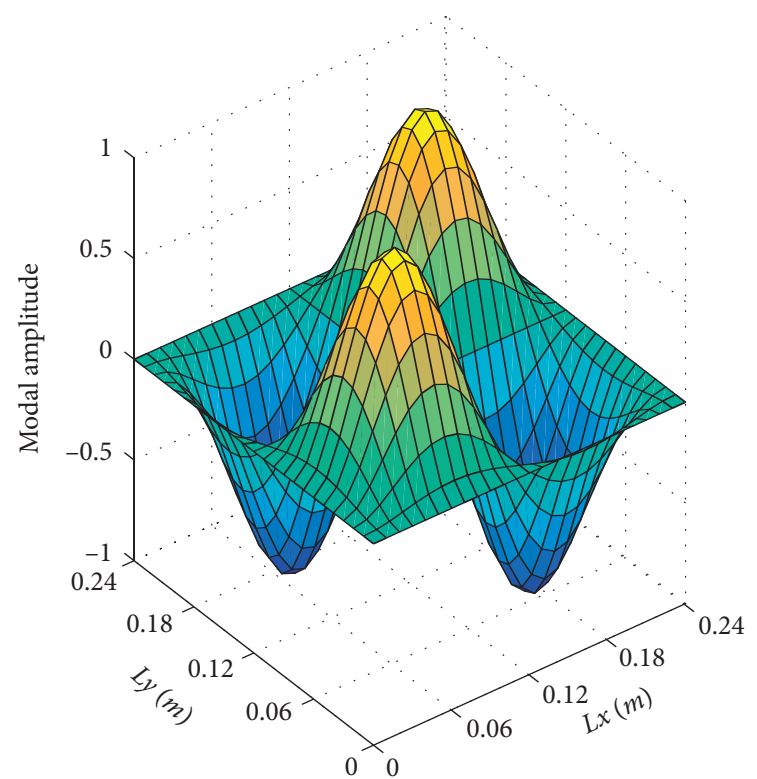

(d)

Figure 7: The first four bending mode shapes of undamaged, fixed conditions plate. (a) Mode 1. (b) Mode 2. (c) Mode 3. (d) Mode 4.

Table 3: Variation of natural frequencies due to crack.

\begin{tabular}{|c|c|c|c|c|c|c|c|c|c|}
\hline \multirow[b]{2}{*}{ Mode } & \multicolumn{3}{|c|}{ Case 1} & \multicolumn{3}{|c|}{ Case 2} & \multicolumn{3}{|c|}{ Case 3} \\
\hline & $\begin{array}{c}\text { Uncracked } \\
(\mathrm{Hz})\end{array}$ & $\begin{array}{c}\text { Cracked } \\
(\mathrm{Hz})\end{array}$ & $\begin{array}{c}\text { Change } \\
(\%)\end{array}$ & $\begin{array}{c}\text { Uncracked } \\
(\mathrm{Hz})\end{array}$ & $\begin{array}{c}\text { Cracked } \\
(\mathrm{Hz})\end{array}$ & $\begin{array}{c}\text { Change } \\
(\%)\end{array}$ & $\begin{array}{c}\text { Uncracked } \\
(\mathrm{Hz})\end{array}$ & $\begin{array}{c}\text { Cracked } \\
(\mathrm{Hz})\end{array}$ & $\begin{array}{c}\text { Change } \\
(\%)\end{array}$ \\
\hline 1 & 112.36 & 112.24 & 0.11 & 168.16 & 168.02 & 0.08 & 308.53 & 308.47 & 0.02 \\
\hline 2 & 164.92 & 164.72 & 0.12 & 422.97 & 422.12 & 0.20 & 633.06 & 632.18 & 0.14 \\
\hline 3 & 209.25 & 209.02 & 0.11 & 422.97 & 422.74 & 0.05 & 633.06 & 632.70 & 0.06 \\
\hline 4 & 292.26 & 291.35 & 0.31 & 675.48 & 674.72 & 0.11 & 932.69 & 931.50 & 0.13 \\
\hline
\end{tabular}

TABle 4: Variation of MAC due to crack.

\begin{tabular}{llll}
\hline Mode & Case 1 & Case 2 & Case 3 \\
\hline 1 & 1.0000 & 1.0000 & 1.0000 \\
2 & 1.0000 & 0.7613 & 0.9964 \\
3 & 1.0000 & 0.8155 & 0.9911 \\
4 & 0.9997 & 1.0000 & 0.9999 \\
\hline
\end{tabular}

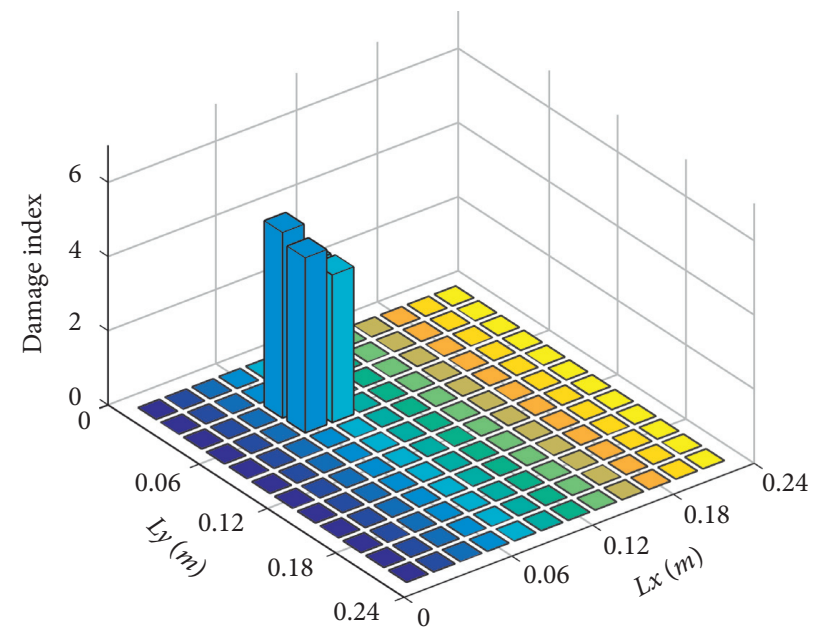

(a)

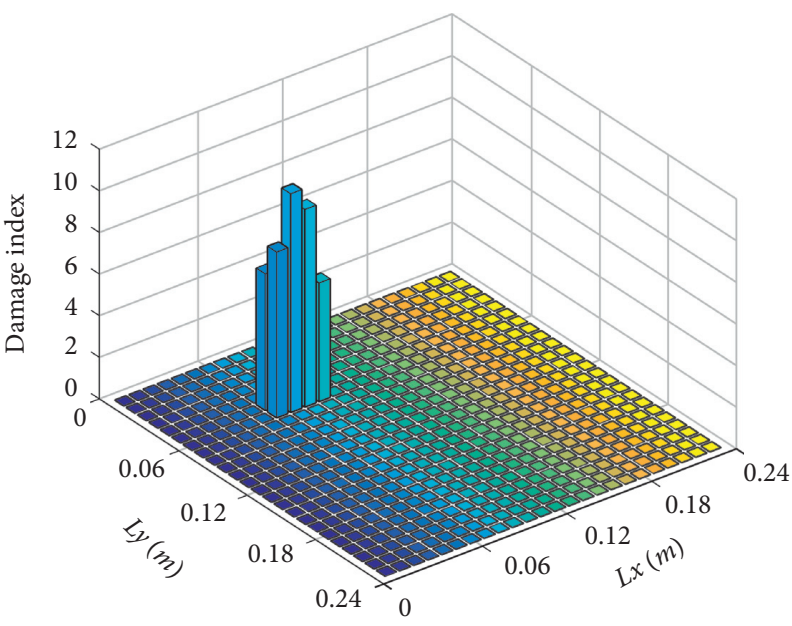

(b)

Figure 8: Continued. 


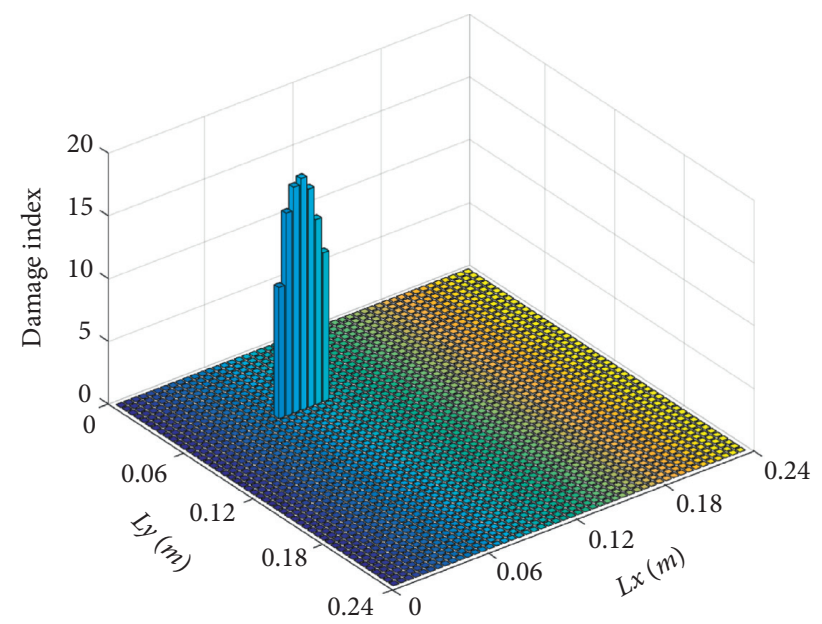

(c)

Figure 8: Damage index charts with different mesh sizes. (a) Mesh $12 \times 12$. (b) Mesh $24 \times 24$. (c) Mesh $48 \times 48$.

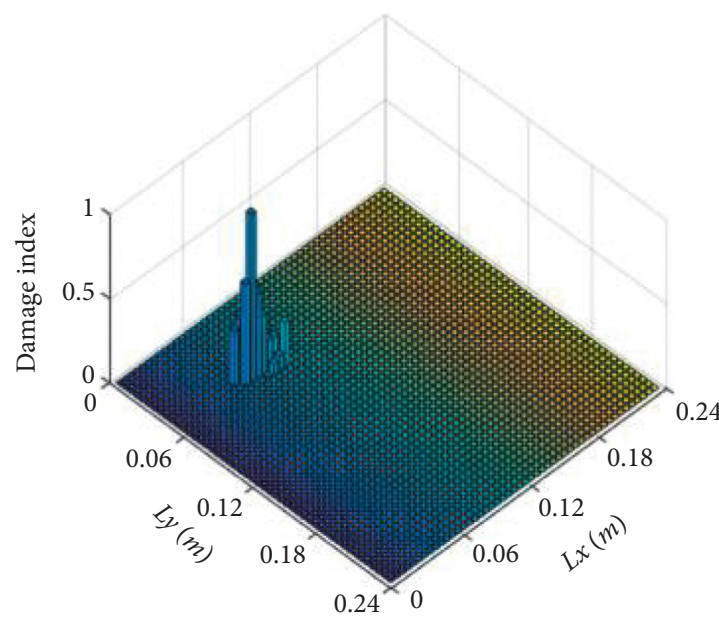

(a)

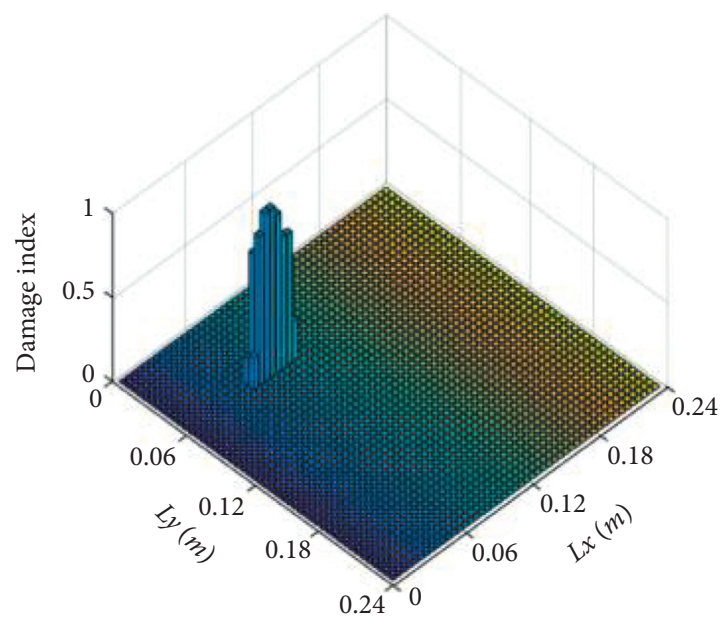

(c)

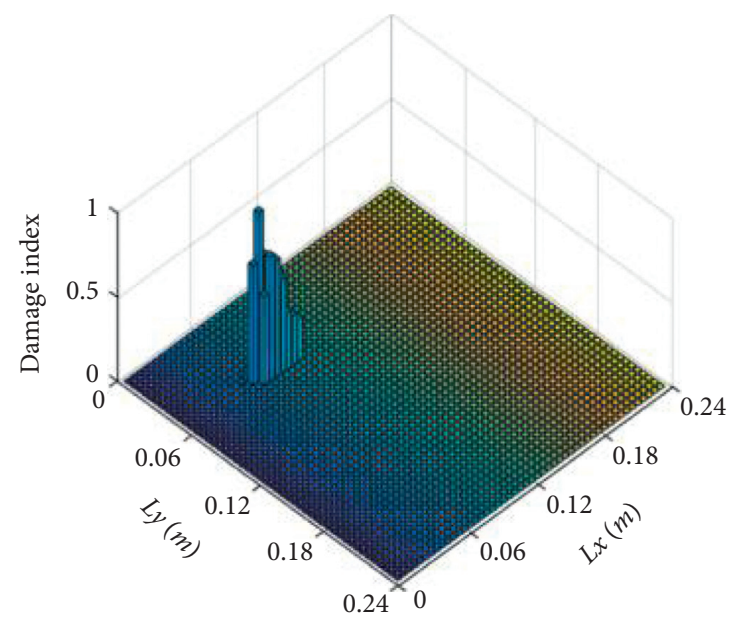

(b)

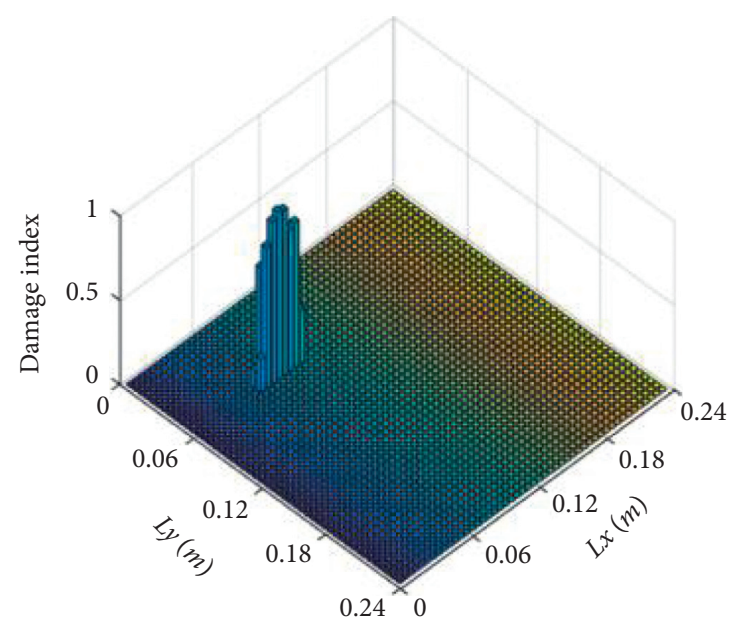

(d)

Figure 9: Damage index charts with damage threshold 50\% $Z_{i j}^{\max }$ for case 1. (a) Mode 1. (b) Modes 1, 2. (c) Modes 1, 2, 3. (d) Modes 1, 2, 3, 4. 


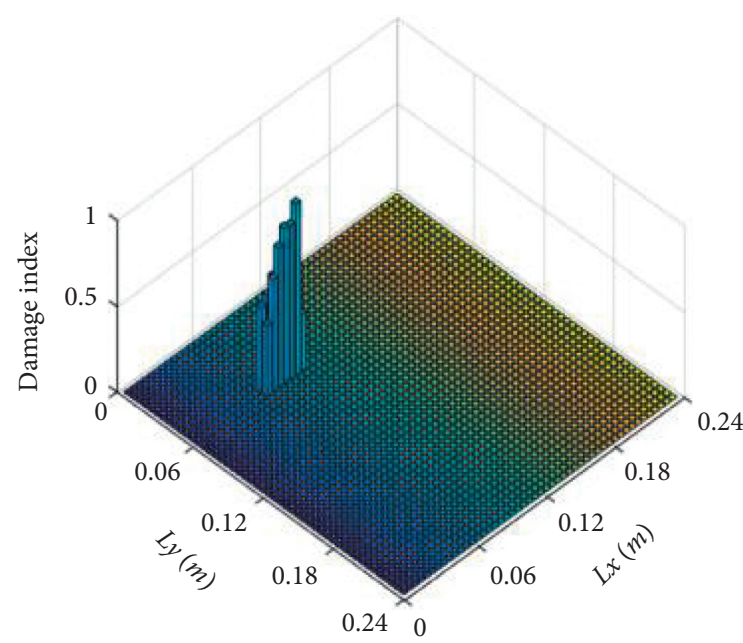

(a)

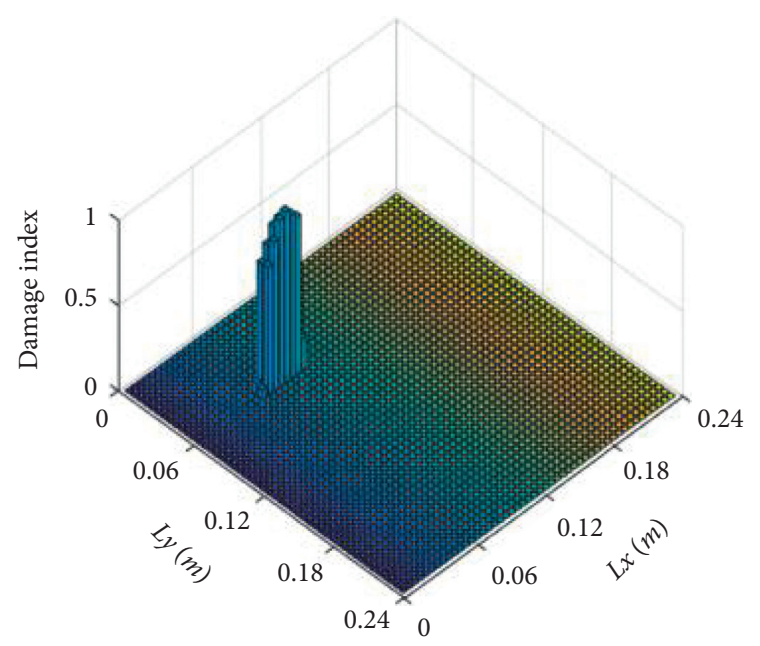

(c)

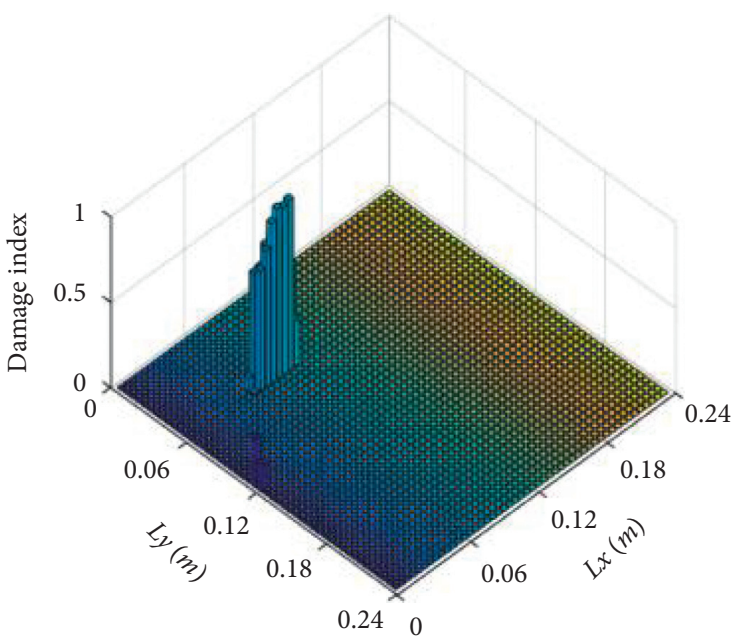

(b)

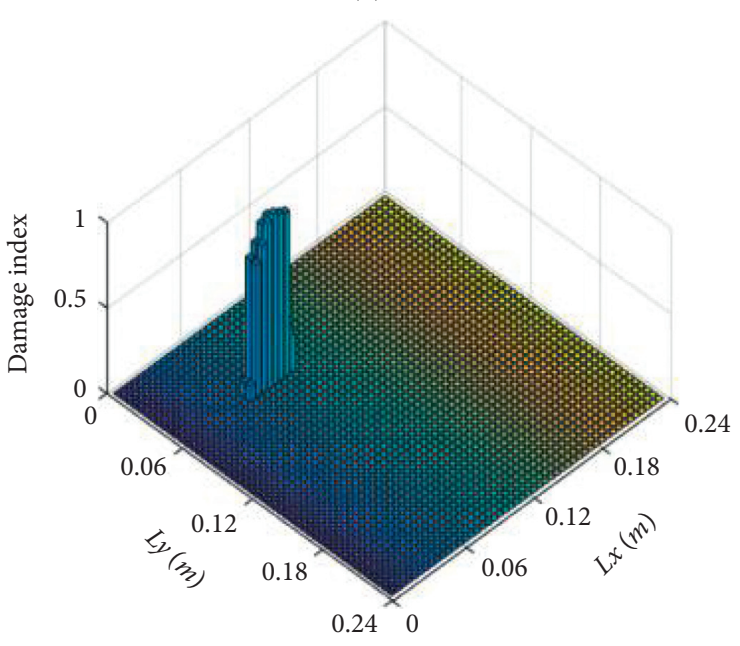

(d)

Figure 10: Damage index charts with damage threshold $50 \% Z_{i j}^{\max }$ for case 2. (a) Mode 1. (b) Modes 1, 2. (c) Modes 1, 2, 3. (d) Modes 1, 2, 3,4 .

predicted. When the damage thresholds increase, DCIs increase till they reach the top level. After that, DCIs decrease because some real damaged elements near the edge of the crack have lower damage indexes than those in the center of cracks and are misdiagnosed. When damage threshold is larger than $50 \% Z_{i j}^{\max }$, most of DCIs get average level.

3.5. Effect of Mode on Damage Detection Results. As listed in Tables 5-7, the sensitivities to damage are also different for each mode. The crack cannot be detected by using single mode for several cases. In case 1, plate with free boundary conditions, mode 3 is the most sensitive to the crack; mode 1 and mode 4 can detect the crack; mode 2 cannot detect the crack. In case 2 , plate with hinged boundary conditions, mode 4 is the most sensitive to the crack; mode 1 and mode 2 can detect the crack; mode 3 cannot detect the crack. Meanwhile, with plate with fixed boundary conditions, mode 4 is also the most sensitive to the crack and mode 1 can detect the crack, but mode 2 and mode 3 cannot detect the crack. The result of crack detection is improved by using combined modes. The use of a combination of two modes, three modes, and four modes can detect the crack. At the same damage threshold, in case of using single mode, the detection of crack length is most accurate when the most sensitive is used. In case of using combined modes, the DCIs get high level in almost used thresholds. With the same thresholds, the DCIs using four modes are better than a combination of three modes. Similarly, DCIs using three modes are higher than only two modes.

\section{Extended Verification}

Damages can usually occur near or along the boundaries of plate-like structures, and it is a quite difficult task to detect the crack at the boundary conditions for damage detection methods. For the purpose of demonstrating the generality and robustness of the proposed method, a $240 \times 360 \mathrm{~mm}$ rectangular plate consisting of two cracks with $40 \mathrm{~mm}$ in length and $10 \mathrm{~mm}$ in width was also investigated. The first 


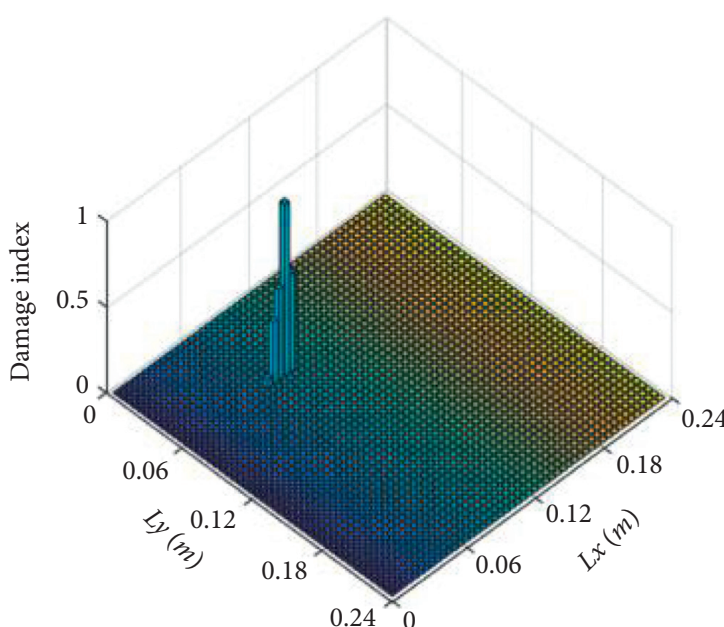

(a)

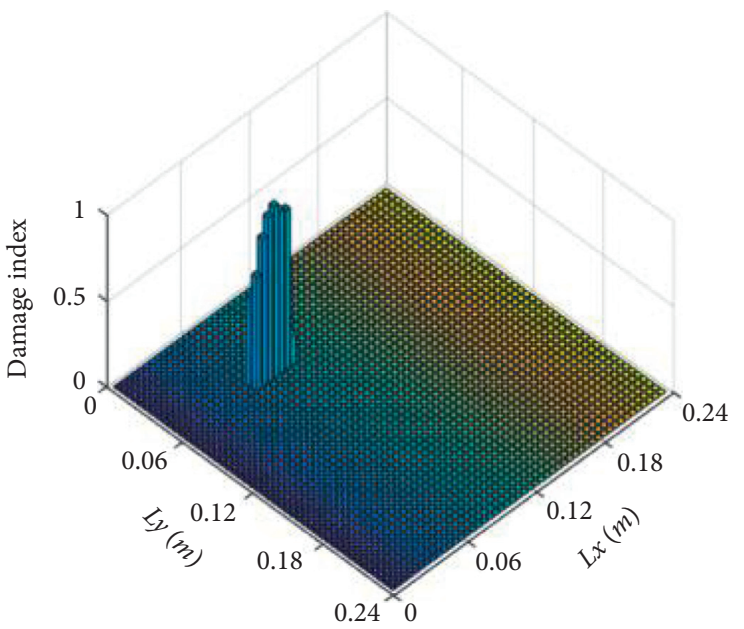

(c)

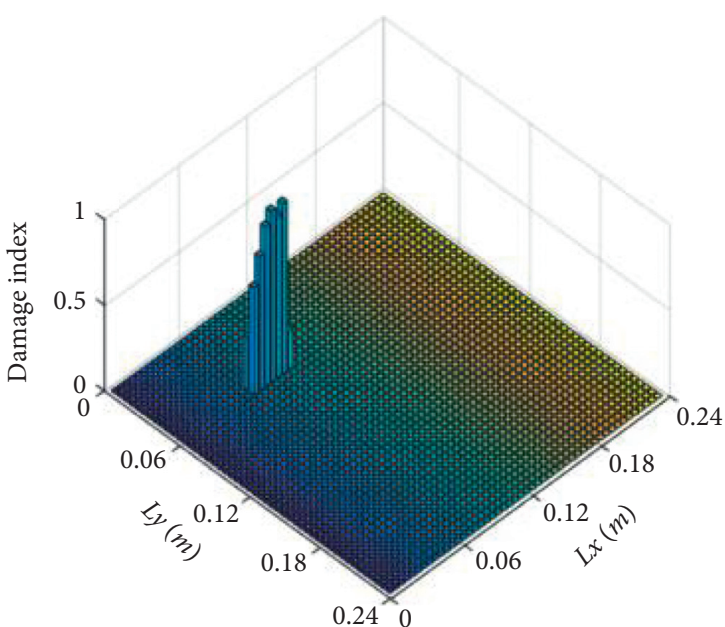

(b)

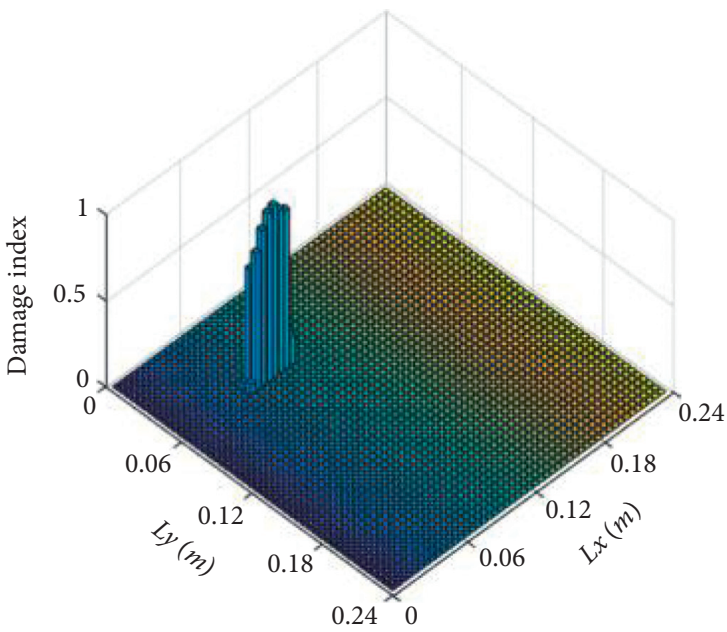

(d)

Figure 11: Damage index charts with damage threshold $50 \% Z_{i j}^{\max }$ for case 3. (a) Mode 1. (b) Modes 1, 2. (c) Modes 1, 2, 3. (d) Modes 1, 2, 3,4 .

TABle 5: Damage capacity indicator for case 1.

\begin{tabular}{lccccccc}
\hline Damage threshold (\%) & Mode 1 & Mode 2 & Mode 3 & Mode 4 & Modes 1, 2 & Modes 1, 2, 3 & Modes 1, 2, 3, 4 \\
\hline 20 & $88(\mathrm{H})$ & $0(\mathrm{~L})$ & $100(\mathrm{H})$ & $100(\mathrm{H})$ & $100(\mathrm{H})$ & $100(\mathrm{H})$ & $100(\mathrm{H})$ \\
30 & $88(\mathrm{H})$ & $0(\mathrm{~L})$ & $100(\mathrm{H})$ & $94(\mathrm{H})$ & $100(\mathrm{H})$ & $100(\mathrm{H})$ & $100(\mathrm{H})$ \\
40 & $75(\mathrm{~A})$ & $0(\mathrm{~L})$ & $100(\mathrm{H})$ & $94(\mathrm{H})$ & $94(\mathrm{H})$ & $100(\mathrm{H})$ & $100(\mathrm{H})$ \\
50 & $56(\mathrm{~A})$ & $0(\mathrm{~L})$ & $100(\mathrm{H})$ & $56(\mathrm{~A})$ & $88(\mathrm{H})$ & $75(\mathrm{H})$ & $81(\mathrm{H})$ \\
60 & $25(\mathrm{~L})$ & $0(\mathrm{~L})$ & $81(\mathrm{H})$ & $25(\mathrm{~L})$ & $56(\mathrm{~A})$ & $75(\mathrm{~A})$ & $88(\mathrm{H})$ \\
70 & $19(\mathrm{~L})$ & $0(\mathrm{~L})$ & $75(\mathrm{~A})$ & $19(\mathrm{~L})$ & & & $75(\mathrm{~A})$ \\
\hline
\end{tabular}

TABLE 6: Damage capacity indicator for case 2.

\begin{tabular}{lccccccc}
\hline Damage threshold (\%) & Mode 1 & Mode 2 & Mode 3 & Mode 4 & Modes 1, 2 & Modes 1, 2, 3 & Modes 1, 2, 3, 4 \\
\hline 20 & $100(\mathrm{H})$ & $100(\mathrm{H})$ & $88(\mathrm{H})$ & $100(\mathrm{H})$ & $100(\mathrm{H})$ & $100(\mathrm{H})$ & $100(\mathrm{H})$ \\
30 & $100(\mathrm{H})$ & $100(\mathrm{H})$ & $75(\mathrm{~A})$ & $100(\mathrm{H})$ & $100(\mathrm{H})$ & $100(\mathrm{H})$ & $100(\mathrm{H})$ \\
40 & $94(\mathrm{H})$ & $100(\mathrm{H})$ & $56(\mathrm{~A})$ & $100(\mathrm{H})$ & $100(\mathrm{H})$ & $100(\mathrm{H})$ & $100(\mathrm{H})$ \\
50 & $94(\mathrm{H})$ & $88(\mathrm{H})$ & $0(\mathrm{~L})$ & $100(\mathrm{H})$ & $100(\mathrm{H})$ & $100(\mathrm{H})$ & $100(\mathrm{H})$ \\
60 & $81(\mathrm{H})$ & $81(\mathrm{H})$ & $0(\mathrm{~L})$ & $81(\mathrm{H})$ & $88(\mathrm{H})$ & $75(\mathrm{~A})$ & $81(\mathrm{H})$ \\
70 & $75(\mathrm{~A})$ & $63(\mathrm{~A})$ & $0(\mathrm{~L})$ & $75(\mathrm{~A})$ & $75(\mathrm{~A})$ & $75(\mathrm{~A})$ & $75(\mathrm{~A})$ \\
\hline
\end{tabular}


TABle 7: Damage capacity indicator for case 3.

\begin{tabular}{lccccccc}
\hline Damage threshold (\%) & Mode 1 & Mode 2 & Mode 3 & Mode 4 & Modes 1, 2 & Modes 1, 2, 3 & Modes 1, 2, 3, 4 \\
\hline 20 & $94(\mathrm{H})$ & $6(\mathrm{~L})$ & $75(\mathrm{~A})$ & $100(\mathrm{H})$ & $100(\mathrm{H})$ & $100(\mathrm{H})$ & $100(\mathrm{H})$ \\
30 & $88(\mathrm{H})$ & $0(\mathrm{~L})$ & $0(\mathrm{~L})$ & $100(\mathrm{H})$ & $100(\mathrm{H})$ & $100(\mathrm{H})$ & $100(\mathrm{H})$ \\
40 & $75(\mathrm{~A})$ & $0(\mathrm{~L})$ & $0(\mathrm{~L})$ & $100(\mathrm{H})$ & $100(\mathrm{H})$ & $100(\mathrm{H})$ & $100(\mathrm{H})$ \\
50 & $44(\mathrm{~L})$ & $0(\mathrm{~L})$ & $0(\mathrm{~L})$ & $100(\mathrm{H})$ & $94(\mathrm{H})$ & $81(\mathrm{H})$ & $75(\mathrm{~A})$ \\
60 & $31(\mathrm{~L})$ & $0(\mathrm{~L})$ & $0(\mathrm{~L})$ & $88(\mathrm{H})$ & $75(\mathrm{H})$ & $75(\mathrm{~A})$ \\
70 & $31(\mathrm{~L})$ & $0(\mathrm{~L})$ & $0(\mathrm{~L})$ & $75(\mathrm{~A})$ & $75(\mathrm{~A})$ & $75(\mathrm{~A})$ \\
\hline
\end{tabular}

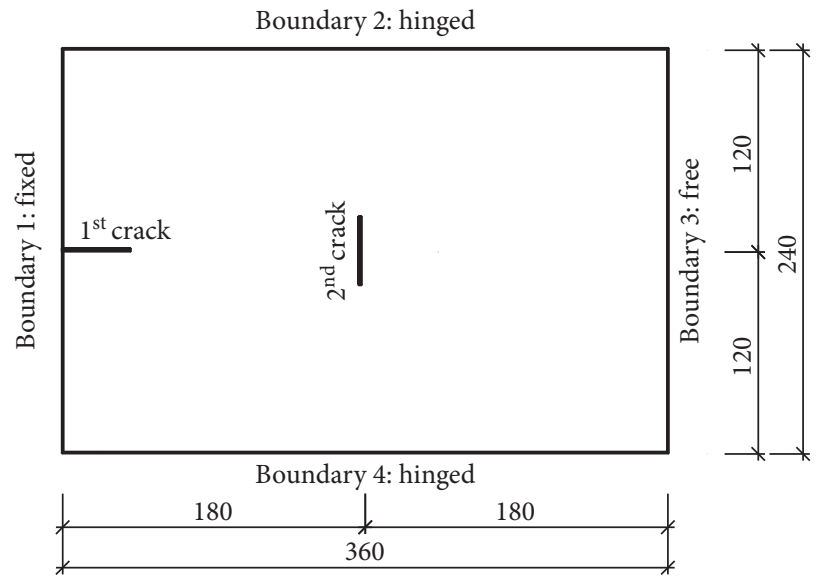

FIgURE 12: Rectangular plate with two cracks.

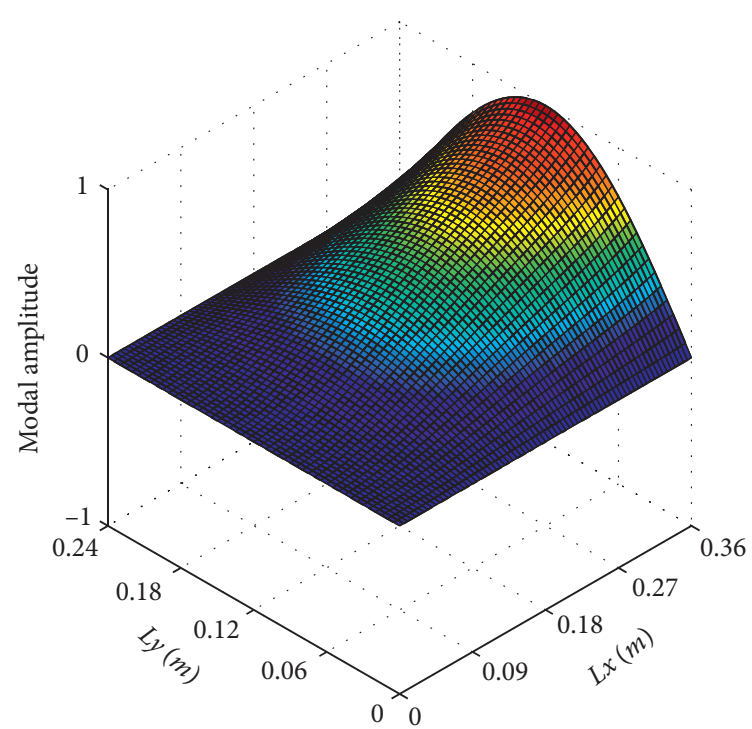

(a)

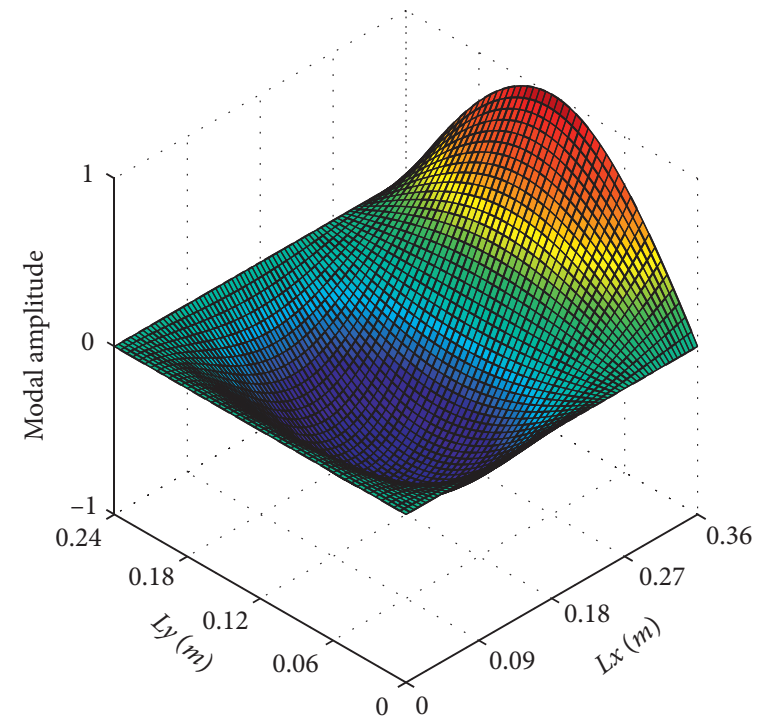

(b)

Figure 13: Continued. 


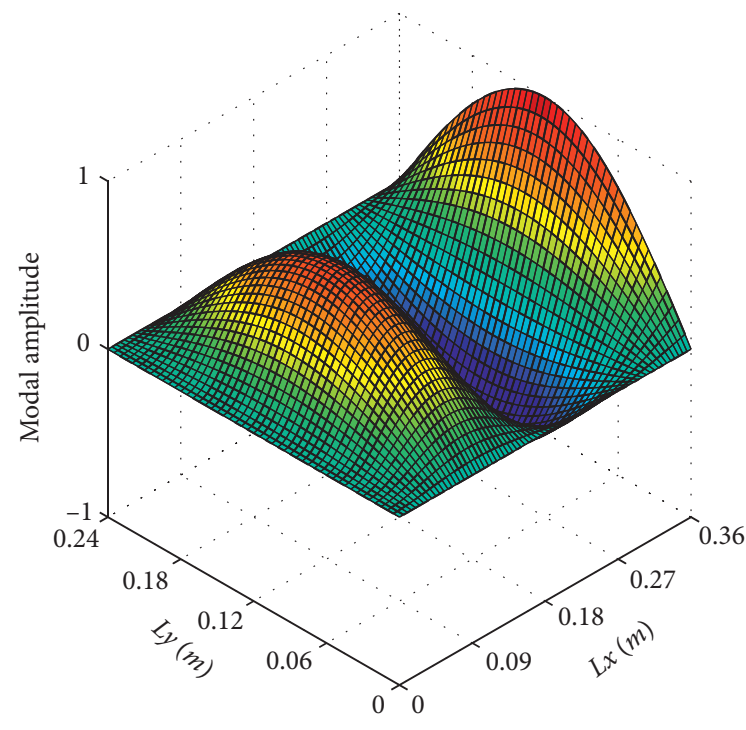

(c)

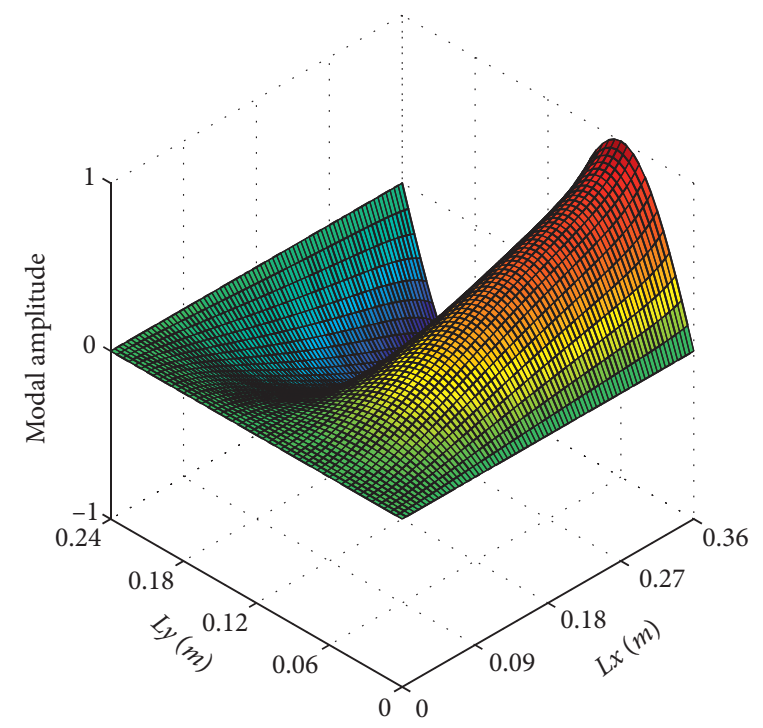

(d)

FIgURE 13: The first four bending mode shapes of undamaged plate. (a) Mode 1. (b) Mode 2. (c) Mode 3. (d) Mode 4.

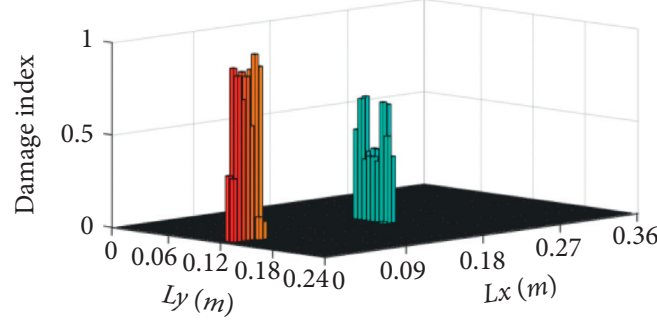

(a)

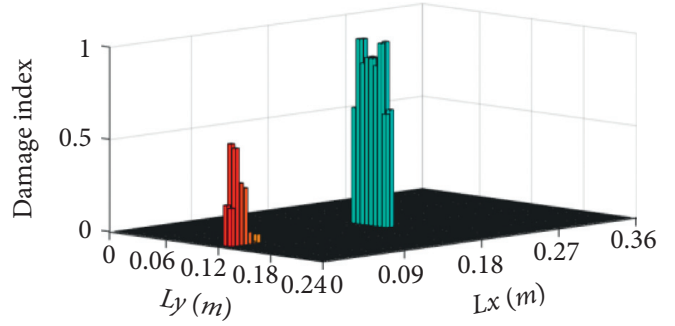

(c)

FIGURE 14: Damage index charts with damage threshold $30 \% Z_{i j}^{\max }$

crack and second crack were assumed with stiffness reductions equal to $50 \%$ and $20 \%$, respectively. The location and direction of cracks were different, one crack in the boundary and another crack in the midspan of the plate (see Figure 12). The material of the plate is aluminum with properties such as elastic modulus of $E=70 \mathrm{GPa}$, Poisson's ratio of $\nu=0.33$, and mass density of $\rho=2735 \mathrm{~kg} / \mathrm{m}^{3}$. The boundary conditions restrained for the plate's four sides were examined as follows: boundary 1 was fixed, boundary 2 and boundary 4 were hinged, and boundary 3 was free.

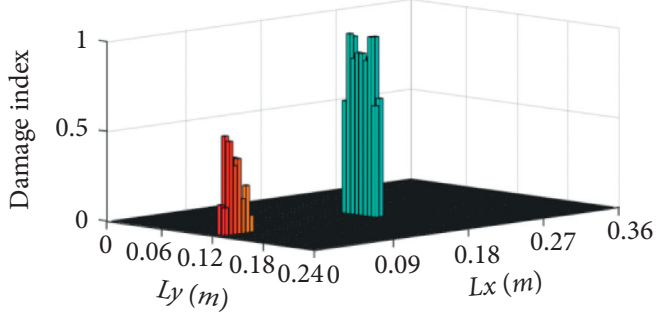

(b)

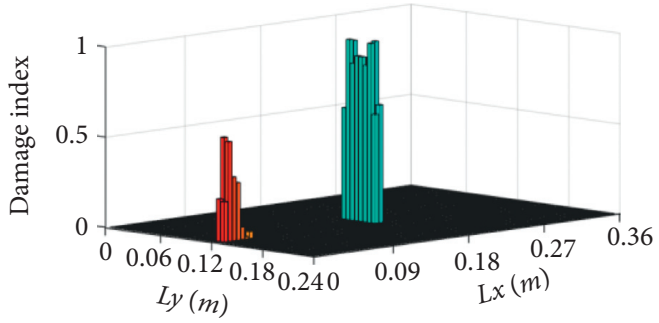

(d)

(a) Mode 1. (b) Modes 1, 2. (c) Modes 1, 2, 3. (d) Modes 1, 2, 3, 4.

Figure 13 shows the first four bending mode shapes of undamaged plates. The proposed method was performed to detect the cracks. Figure 14 shows the damage index charts with damage threshold $30 \% Z_{i j}^{\max }$. Both of the two cracks were successfully detected by using the proposed method. The results of crack detection for the target plate are summarized in Table 8. With the combination of the first three modes and the damage threshold of $30 \% Z_{i j}^{\max }$, although DCI does not reach $100 \%$, it still has a high level of $88 \%$. This proves that the proposed method can detect 
TABLE 8: Damage capacity indicator for extended verification case.

\begin{tabular}{lccccccc}
\hline Damage threshold (\%) & Mode 1 & Mode 2 & Mode 3 & Mode 4 & Modes 1, 2 & Modes 1, 2, 3 & Modes 1, 2, 3, 4 \\
\hline 20 & $94(\mathrm{H})$ & $88(\mathrm{H})$ & $72(\mathrm{~A})$ & $75(\mathrm{~A})$ & $94(\mathrm{H})$ & $94(\mathrm{H})$ & $94(\mathrm{H})$ \\
30 & $94(\mathrm{H})$ & $84(\mathrm{H})$ & $56(\mathrm{~A})$ & $53(\mathrm{~A})$ & $91(\mathrm{H})$ & $88(\mathrm{H})$ & $88(\mathrm{H})$ \\
40 & $94(\mathrm{H})$ & $69(\mathrm{~A})$ & $44(\mathrm{~L})$ & $41(\mathrm{~L})$ & $88(\mathrm{H})$ & $75(\mathrm{~A})$ & $75(\mathrm{~A})$ \\
50 & $94(\mathrm{H})$ & $56(\mathrm{~A})$ & $41(\mathrm{~L})$ & $38(\mathrm{~L})$ & $69(\mathrm{~A})$ & $69(\mathrm{~A})$ & $69(\mathrm{~A})$ \\
60 & $56(\mathrm{~A})$ & $50(\mathrm{~A})$ & $38(\mathrm{~L})$ & $31(\mathrm{~L})$ & $56(\mathrm{~A})$ & $56(\mathrm{~A})$ & $56(\mathrm{~A})$ \\
70 & $50(\mathrm{~A})$ & $47(\mathrm{~L})$ & $31(\mathrm{~L})$ & $22(\mathrm{~L})$ & $50(\mathrm{~A})$ & $50(\mathrm{~A})$ & $53(\mathrm{~A})$ \\
\hline
\end{tabular}

accurately the multiple cracks of plate-like structures with various boundary conditions.

\section{Conclusions}

In this study, a vibration-based crack detection method using modal strain energy was developed successfully for plate-like structures with various boundary conditions. A detection capacity indicator was newly presented to assess the capacity of crack's location and length detection in plates. The feasibility of the proposed method was verified by a rectangular aluminum plate with three different boundary conditions such as free, hinged, and fixed conditions. The effects of element's mesh size, damage threshold, and mode on damage detection results were also evaluated. An extended verification was also performed to demonstrate the robustness of the proposed method. From the analyzed results, the conclusions were drawn as follows: (1) the proposed method was capable of accurate crack detection in plates with various boundary conditions for appropriate modes and damage thresholds; (2) the use of combination of the first three bending modes with damage threshold of $30 \%$ of the maximum damage index was good enough to accurately crack detection in plates. The proposed method can be employed in conjunction with other damage detection methods, especially local damage detection methods and artificial intelligence algorithms, to enhance the efficiency and accuracy of detection results in the field of structural health monitoring.

\section{Data Availability}

The data used to support the findings of this study are included within the article.

\section{Conflicts of Interest}

The authors declare that there are no conflicts of interest regarding the publication of this paper.

\section{Acknowledgments}

This research was funded by Ho Chi Minh City University of Technology (HCMUT), VNU-HCM, under grant number T-KTXD-2019-13. The authors would like to thank Ho Chi Minh City University of Technology (HCMUT), VNUHCM, for the support of time and facilities for this study.

\section{References}

[1] S. W. Doebling, C. R. Farrar, and M. B. Prime, "A summary review of vibration-based damage identification methods," The Shock and Vibration Digest, vol. 30, no. 2, pp. 91-105, 1998.

[2] C. R. Farrar, Historical Overview of Structural Health Monitoring", Lecture Notes on Structural Health Monitoring Using Statistical Pattern Recognition, Los Alamos Dynamics, Los Alamos, NM, USA, 2001.

[3] J.-T. Kim, T.-C. Huynh, and S.-Y. Lee, "Wireless structural health monitoring of stay cables under two consecutive typhoons," Structural Monitoring and Maintenance, vol. 1, no. 1, pp. 47-67, 2014.

[4] H.-N. Li, T.-H. Yi, L. Ren, D.-S. Li, and L.-S. Huo, "Reviews on innovations and applications in structural health monitoring for infrastructures," Structural Monitoring and Maintenance, vol. 1, no. 1, pp. 1-45, 2014.

[5] H. Sohn, C. R. Farrar, F. M. Hemez, D. D. Shunk, D. W. Stinemates, and B. R. Nadler, A Review of Structural Health Monitoring Literature: 1996-2001, Los Alamos National Laboratory, Los Alamos, NM, USA, 2003.

[6] W. Fan and P. Qiao, "Vibration-based damage identification methods: a review and comparative study," Structural Health Monitoring, vol. 10, no. 1, pp. 83-111, 2011.

[7] N. Stubbs, J. T. Kim, and C. R. Farrar, "Field verification of a nondestructive damage localization and sensitivity estimator algorithm," in Proceedings of the 1995 13th International Modal Analysis Conference, pp. 210-218, Nashville, TN, USA, February 1995.

[8] N. Stubbs and J. T. Kim, "Damage localization in structures without baseline modal parameters," AIAA Journal, vol. 34, no. 8, pp. 1649-1654, 1996.

[9] P. Cornwell, S. W. Doebling, and C. R. Farrar, "Application of the strain energy damage detection method to plate-like structures," Journal of Sound and Vibration, vol. 224, no. 2, pp. 359-374, 1999.

[10] J.-T. Kim, Y.-S. Ryu, H.-M. Cho, and N. Stubbs, "Damage identification in beam-type structures: frequency-based method vs mode-shape-based methodfication in beam-type structures: frequency-based method vs mode shape-based method," Engineering Structures, vol. 25, no. 1, pp. 57-67, 2003.

[11] J.-T. Kim, J.-H. Park, D.-S. Hong, and W.-S. Park, "Hybrid health monitoring of prestressed concrete girder bridges by sequential vibration-impedance approaches," Engineering Structures, vol. 32, no. 1, pp. 115-128, 2010.

[12] H.-W. Hu and C.-B. Wu, "Nondestructive damage detection of two dimensional plate structures using modal strain energy method," Journal of Mechanics, vol. 24, no. 4, pp. 319-332, 2008.

[13] A. Dixit and S. Hanagud, "Single beam analysis of damaged beams verified using a strain energy based damage measure," 
International Journal of Solids and Structures, vol. 48, no. 3-4, pp. 592-602, 2011.

[14] S. M. Seyedpoor, "A two stage method for structural damage detection using a modal strain energy based index and particle swarm optimization," International Journal of Non-Linear Mechanics, vol. 47, no. 1, pp. 1-8, 2012.

[15] Y.-J. Cha and O. Buyukozturk, "Structural damage detection using modal strain energy and hybrid multiobjective optimization," Computer-Aided Civil and Infrastructure Engineering, vol. 30, no. 5, pp. 347-358, 2015.

[16] D. T. Vo, H. V. Ho, T. H. Dang, and T. T. Nguyen, "A two-step approach for damage detection in laminated composite structures using modal strain energy method and an improved differential evolution algorithm," Composite Structures, vol. 147, pp. 42-53, 2016.

[17] A. Kaveh and A. Zolghadr, "Cyclical parthenogenesis algorithm for guided modal strain energy based structural damage detection," Applied Soft Computing, vol. 57, pp. 250-264, 2017.

[18] C. D. Dinh, D. T. Vo, H. V. Ho, and T. T. Nguyen, "Damage assessment in plate-like structures using a two-stage method based on modal strain energy change and Jaya algorithm," Inverse Problems in Science and Engineering, vol. 27, no. 2, pp. 166-189, 2018.

[19] K. Samir, A. W. Magd, D. Boutchicha, and K. Tawfiq, "Structural health monitoring using modal strain energy damage indicator coupled with teaching-learning-based optimization algorithm and isogoemetric analysis," Journal of Sound and Vibration, vol. 448, pp. 230-246, 2019.

[20] S. Wang, Y. Jiang, M. Xu, Y. Li, and Z. Li, "Structural damage identification using an iterative two-stage method combining a modal energy based index with the BAS algorithm," Steel and Composite Structures, vol. 36, no. 1, pp. 31-45, 2020.

[21] S. S. Kourehli, "Damage identification of structures using second order approximation of Neumann series expansion," Journal of Rehabilitation in Civil Engineering, vol. 27, no. 2, pp. 81-91, 2020.

[22] P. Ghannadi, S. S. Kourehli, M. Noori, and W. A. Altabey, "Efficiency of grey wolf optimization algorithm for damage detection of skeletal structures via expanded mode shapes," Advances in Structural Engineering, vol. 23, no. 13, pp. 2850-2865, 2020. 